NBER WORKING PAPER SERIES

\title{
WHERE HAVE ALL THE CHILDREN GONE? AN EMPIRICAL STUDY OF CHILD ABANDONMENT AND ABDUCTION IN CHINA
}

\author{
Xiaojia Bao \\ Sebastian Galiani \\ Kai Li \\ Cheryl Long \\ Working Paper 26492 \\ http://www.nber.org/papers/w26492 \\ NATIONAL BUREAU OF ECONOMIC RESEARCH \\ 1050 Massachusetts Avenue \\ Cambridge, MA 02138 \\ November 2019, Revised April 2020
}

The views expressed herein are those of the authors and do not necessarily reflect the views of the National Bureau of Economic Research.

At least one co-author has disclosed a financial relationship of potential relevance for this research. Further information is available online at http://www.nber.org/papers/w26492.ack

NBER working papers are circulated for discussion and comment purposes. They have not been peer-reviewed or been subject to the review by the NBER Board of Directors that accompanies official NBER publications.

(C) 2019 by Xiaojia Bao, Sebastian Galiani, Kai Li, and Cheryl Long. All rights reserved. Short sections of text, not to exceed two paragraphs, may be quoted without explicit permission provided that full credit, including $(\odot$ notice, is given to the source. 
Where Have All the Children Gone? An Empirical Study of Child Abandonment and Abduction in China

Xiaojia Bao, Sebastian Galiani, Kai Li, and Cheryl Long

NBER Working Paper No. 26492

November 2019, Revised April 2020

JEL No. J12

\section{ABSTRACT}

In the past 40 years, a large number of children have been abandoned or abducted in China. We argue that the implementation of the one-child policy has significantly increased both child abandonment and child abduction and that, furthermore, the cultural preference for sons in China has shaped unique gender-based patterns whereby a majority of the children who are abandoned are girls and a majority of the children who are abducted are boys. We provide empirical evidence for the following findings:(1) Stricter one-child policy implementation leads to more child abandonment locally and more child abduction in neighboring regions; (2) A stronger sonpreference bias in a given region intensifies both the local effects and spatial spillover effects of the region's one-child policy on child abandonment and abduction; and (3) With the gradual relaxation of the one-child policy after 2002, both child abandonment and child abduction have dropped significantly. This paper is the first to provide empirical evidence on the unintended consequences of the one-child policy in terms of child trafficking in China.

Xiaojia Bao

422 South Siming Road

A312 Economics Building

Xiamen University

Xiamen, 361005

Fujian

China

xiaojiabao@xmu.edu.cn

Sebastian Galiani

Department of Economics

University of Maryland

3105 Tydings Hall

College Park, MD 20742

and NBER

galiani@econ.umd.edu
Kai Li

422 South Siming Road

Economics Building B502B

Xiamen University

Xiamen, Inte 361005

China

likai501@gmail.com

Cheryl Long

Xiamen University

Xiamen, Fujian 361005

China

cxlong@xmu.edu.cn 


\section{Introduction}

The phenomenon of missing girls due to prenatal sex selective abortion has attracted much academic attention (Sen, 1990; Ebenstein, 2010; Chen, Li and Meng, 2013; Jayachandran, 2017; Almond, Li and Zhang, 2019). But in reality there is another serious type of missing children problem, which is boys and girls abandoned or abandoned after birth (O'Connell Davidson, 2011; The State Council, 2011). Although there lack accurate reports, the estimated number of abandoned and abducted children in China ranges from tens of thousands ${ }^{2}$ to hundreds of thousands a year ${ }^{3}$, and many of these children end up being trafficked into illegal adoptions (Cai and Lavaly, 2003; Liu, Larsen and Wyshak, 2004; Zhang, 2006; Chen et al., 2015), causing long-lasting social and economic impacts. ${ }^{4}$ Poverty has generally been identified as one of the key reasons for missing children (Dessy, Mbiekop and Pallage, 2005; Tamura, 2010; Anderson and Ray, 2010; Corno and Voena, 2019). Yet, surprisingly, in light of China's continuing rapid economic growth, the number of missing children has remained high. In this paper, we explore the institutional and cultural reasons behind this rampant problem.

The greatest challenge to undertake a study on missing children is the lack of data. Taking advantage of a recently developed database on family-reported missing persons maintained by the website of Baby Come Back Home (BCBH) (https://baobeihuijia.com/Index.aspx) ${ }^{5}$ currently the largest online platform and nongovernmental organization dedicated to locating missing children in China, we construct a record of missing child cases for local regions since 1950. As of June 2018,

\footnotetext{
2 Legal Daily, The Ministry of Public Safety Retrieved 43,000 Abducted Women and Children in 2014, February 16, 2015, http://legal.people.com.cn/n/2015/0216/c188502-26574114.html

${ }^{3}$ Human Trafficking Research Organization, (2014), Human Trafficking in China by Michelle Lillie, https://humantraffickingsearch.org/human-trafficking-in-china/

4 According to the International Labour Organization (ILO) and Walk Free Foundation, around 5.5 million children under 18 have been victims of child trafficking (ILO, 2017).

5 The Baby Come Back Home (BCBH) website maintains two main databases on missing children. One contains reports filed by families looking for their children; the other contains reports filed by child victims looking for their biological families.
} 
the database included 16,969 child abandonment reports and 24,175 child abduction reports filed by their families. The number of reported missing children shows a clear humpback pattern: Compared to its pre-1979 level, the number of reported missing children increased by more than 9 times during the 1980s-1990s, which corresponds to the period of strict implementation of the one-child policy in China.

To offer an explanation for the seemingly counter-intuitive increase in child abandonment and abduction during a period of economic prosperity, we turn to the implementation of the one-child policy combined with the cultural preference for sons in China (Hesketh and Zhu, 2006; Almond and Edlund, 2008; Dahl and Moretti, 2008; Qian, 2008; Alesina, Giuliano and Nunn, 2018). The economic logic is as follows: Under the one-child policy ${ }^{6}$, families that exceeded the birth quota faced such punishments as financial penalties, deprivation of promotion opportunities and even potential job losses (Scharping, 2013; Howden and Zhou, 2014), making it very costly for parents to consider having a child beyond the quota. Furthermore, in a culture where sons are preferred over daughters, families might resort to prenatal sex-selection options or postnatal measures to meet their desired gender mix in face of birth quota restrictions. For postnatal options, the attractiveness of either one of two alternatives thus increases, with one option being the abandonment of a baby girl to give the parents an opportunity to have another child and the other being the purchase of a young boy by means of illegal adoption of an abducted or trafficked child. This explanation is also supported by findings that children abandoned are mostly girls (Chen et al., 2015; Xing, 2015) while children abducted are mostly boys (Johnson, Huang and Wang, 1998; Li, Ren and Zhang, 2013; Xing, Chen and Xu, 2013; Tao, 2017).

We explore the impacts of the one-child policy on missing children using both regional and temporal variations in penalty fines and reported missing child cases at the level of

\footnotetext{
${ }^{6}$ While China's birth control policy was never able to achieve a fertility rate close to 1 , we use the term one-child policy $(O C P)$ to refer to the policy that punishes families that give more than one birth, as it is the most commonly used term in the literature.
} 
local prefectures. Following Ebenstein (2010), Scharping (2013), and Huang, Lei and Sun (2016), we measure the stringency of the enforcement of the one-child policy at the provincial level using the ratio between the fine levied for the first unauthorized birth and the local average per capita annual income. Local provincial governments had much flexibility in setting the level of local fines following the guidelines of the central government, and as a result, there is substantial regional and temporal variations during the study period of 1988-2001. As an income-relative indicator, this fine measurement already accounts for the first-order relationship between the absolute fine amount and income level. Indeed, we find that the average penalty did not vary across provinces as a function of local variables, such as income, the quality of transportation infrastructure and economic and fiscal conditions, indicating that local fine level is likely exogenous to economic factors. There is, however, an argument the penalty fine might be affected by politicians' promotion incentives, which vary with politicians' personal characteristics (Huang, Lei and Zhao, 2016). Consistent with this argument, we find a significant correlation between local penalty fine and local politicians' term length. Therefore, we control for these politicians' characteristics when analyzing the relationship between penalty fine and missing children to take into account of the role of politicians' promotion pressure in both fine and missing children in local regions.

Our results show that stricter one-child policy characterized by higher fine level lead to increases in the number of family-reported child abandonment cases between 1988 and 2001. On average, when the penalty fine increases by the same amount as local disposable income, the number of reported child abandonment cases increased by 0.3 , which accounts for a $14 \%$ increase of the reported child abandonment cases at the prefectural level. However, the positive impact is only significant for the abandonment of girls, not for boys. These results imply that families abandon girls increasingly, in order to avoid higher penalty fines for exceeding the birth quota while still having the opportunity to have another (potentially) male child, as the burden of the penalty increases. This is consistent with the existent general population's preference for sons. 
In contrast to the local effect of these fines on child abandonment, the size of the fine mainly had an impact on the child abduction rate in neighboring regions. When the average fine of a prefecture's immediate neighbors increased by the same amount as the average income in those provinces, one more child was reported to be abducted from the prefecture. This accounts for a $35.7 \%$ increase of the reported child abductions locally. Unlike child abandonment, the impact of the average level of neighbors' fines on local child abduction cases was only significant for boys. This is also consistent with the gender composition pattern whereby most abandoned children were girls and most of the abducted children were boys. As the cultural preference for sons increased the demand for the adoption of boys because of birth quota restrictions, the market price for boys rose relative to the market price for girls. Thus, given similar costs for the abduction of children of either sex, it became more lucrative for traffickers to abduct boys. When breaking down the neighboring effect of fine on child abduction by specific distance ranges, we find that the level of fines mainly increases child abduction in prefectures located between $300 \mathrm{~km}$ and $600 \mathrm{~km}$ away. This result is consistent with the previous finding about child trafficking distance (Wang et al., 2018), since traffickers have to balance transportation costs with the possibility of being caught by parents or law enforcement officers.

The general preference for sons not only shapes the contrasting gender patterns of child abandonment versus child abduction, but also intensifies the impact of the one-child policy on the incidence of missing children. Using the male-to-female ratio at birth as an indicator of local gender-preference bias, ${ }^{7}$ we find the positive impact of these fines on child abandonment to be greater in regions with a stronger preference for sons. This is consistent with the hypothesis that families that prefer male heirs are more likely to abandon a previously born girl so that they can have the chance of giving birth to a boy in the future while remaining within the birth quota. The positive spillover impact of

\footnotetext{
7 The preference for male children has been shown to originate from agricultural practices (Alesina, Giuliano and Nunn, 2013 and 2018) and institutional arrangements concerning property rights (Bhalotra et al., 2019).
} 
these fines on child abduction in neighboring regions is also found to be stronger if the gender-preference bias is greater, which is again in line with the argument that the birth control policy is an explanatory variable for child trafficking: An increase in the fines in a prefecture with a stronger gender bias leads to a greater increase in the number of children abducted from neighboring regions, and a stronger demand for boys in a region where birth control policies are more strictly enforced prompts traffickers to abduct more boys from neighboring regions.

Penalty fine affects child abandonment and child abduction differently in different age groups for children. Higher penalty fines lead to increases in abandonment of newborns instead of older children. This is probably because the decision to abandon a girl child is often made quite early on for two reasons: first, as the family's objective is to keep within the birth quota so that there is a chance of having a boy in the future, it is desirable to prevent people from learning about the birth; and, second, it would become harder to abandon the child as emotional attachment grows over time. By contrast, children in the 1-to-4 year age group are more vulnerable to abduction than children in other age groups when neighboring regions' enforcement of the one-child policy becomes stricter, but the stringency of neighboring provinces' enforcement of the onechild policy does not significantly affect the likelihood that either newborns or children older than 5 years of age will be abducted. While the reason for newborns being rarely abducted is straightforward ---infants are usually kept at home and, thus, the abduction cost will be high--- the reason for the rarity of abductees older than 5 years of age is that families generally prefer to adopt younger children, before they develop long-term memories. The results for rates of child abduction in different age groups are also consistent with the observation that the price paid for an abducted boy tends to be higher for younger boys (Shen, Antonopoulos and Papanicolaou, 2013).

The positive impacts of penalty fine on missing children rely on the high collection rate of fines. If fine collection rate is low, families might no longer incorporate the penalty fine in their decision making of child raising especially beyond-quota births. Following 
the Law on Population and Family Planning in 2001, the implementation of the onechild policy generally became more relaxed with less brutal asset confiscation and lower fine collection rate (Shi, 2006; Gao and Lu, 2006), until 2016 when the one-child policy came to a full stop. As a placebo test, we studied the period from 2002 to 2016 when the one-child policy is still in place but with a much more relaxed implementation. We didn't find significant impacts of fines on child abandonment and child abduction similar to the significant effect for the period from 1988 to 2001.

One important potential concern about our study is the possible under-reporting of missing children. We show that our results are unlikely to be biased by the underreporting driven by information access due to income, likelihood to survive until the period to use the $\mathrm{BCBH}$ service, and intension to report a missing child case. Our results are robust to using the logarithm of the number of child abandonment and abduction cases, excluding major prefectures that are perceived as top destinations for child trafficking and excluding minority autonomous regions that have less gender bias than the Han-dominated regions. The results also remain robust when including additional controls such as the local income level and the total number of children in the local prefecture. The results are also not contaminated by the concern of misreporting of child abandonment as child abduction. Due to potential moral pressure, families may report child abandonment as child abduction, resulting in more underreporting of child abandonment relative to child abduction.

We also rule out the potential confounding effects of other policies and changes which occurred around the same time as the one-child policy, especially the Household Responsibility System (HRS) land reform (Almond, Li and Zhang, 2019) and the penetration of prenatal sex selection technologies (Chen, Li and Meng, 2013). First of all, our main analysis covers the time period of 1988-2001, whereas the HRS land reform that began in 1978 had completed by 1984 throughout the country (Lin, 1992). By this period, the use of prenatal sex-diagnostic technology and sex-selective abortions had become widely spread throughout Chinese counties, there is very little 
variation in the availability of such technologies during much of our sample period to explain the patterns in missing children. Secondly, we find no significant differences in the effects of one-child policy penalty fines on missing children in rural versus urban regions during 1988-2001, which suggests that post-birth gender selection through child abandonment and abduction existed in both rural and urban regions universally. In fact, more than $70 \%$ of abandonment and abduction cases in our data occurred in urban areas, which were not affected by the HRS land reform directly. The similar response of missing children in rural and urban regions in response to penalty fines suggest that access to prenatal sex selection technologies didn't not affect our findings about the relationship.

This paper extends current studies on families' options to achieve the desired gender ratio, by focusing on post-birth options instead of pre-birth options. For pre-birth gender selection, the use of prenatal sex-diagnostic technology and sex-selective abortions are perceived to be a key reason causing the excessive male-female sex ratio at birth and the large number of "missing" unborn girls in cultures with strong son-preferences, such as India and China (Chen, Li and Meng, 2013; Jayachandran, 2017; Almond, Li and Zhang, 2019). However, families' gender discrimination behaviors continue after child birth, through differential degree of neglect (Jayachandran and Kuziemko, 2011) and gender-biased resource allocation in health care and medical attention (Sen, 1990). To the best of our knowledge, this paper is the first empirical study to explore the institutional factors involved in child abandonment and abduction. And by studying another unintended consequence of the one-child policy in China, it also contributes to the general body of literature on the economics of crime and on population control policies (Edlund et al., 2013).

The rest of this analysis is organized as follows. In Section 2, we provide background information on the one-child policy and penalty fines in China. Section 3 introduces our data on missing children and the potential under-reporting bias. Section 4 discusses our theoretical hypotheses and the empirical model used to relate the birth control 
policy to the number of missing children in China. Section 5 presents our results and robustness checks, while Section 6 concludes.

\section{One-Child Policy and Penalty Fines}

China's one-child policy was first introduced in 1979 and remained in place until 2016 (Ebenstein, 2010; Zhang, 2017), when it was replaced by the two-child policy. Under the one-child policy, most families were restricted by birth quota. ${ }^{8}$ Both pre-birth authorization and after-birth penalties and rewards are implemented to ensure the policy's effective implementation. Before a birth, a family was required to obtain a birth certificate (Sheng Yu Fu Wu Zheng), which was typically released after verification that the family was under the birth quota. If a family had an unauthorized birth, various penalties would apply, including fines, deprivation of promotion opportunities and/or potential demotion of the parents. Families obeying the one-child policy were rewarded with certificates of merit, cash awards, favorable pension arrangements and the promise of priority status for receiving schooling and medical services (Wei and Zhang, 2014; Whyte, Feng and Cai, 2015). Families that had already used their birth quota were also encouraged to have birth control operations, such as intrauterine device (IUD) insertion and sterilization procedures.

Of the various policy instruments in place, fines for parents who violated the birth quota requirement have been the main punitive mechanism for enforcing the one-child policy. The amount of penalty fines is specified in provincial regulations on family planning (Ji Hua Sheng Yu Tiao Li) following general guidelines of the family planning law released by the central government. Throughout much of this period, the central government gave provincial governments full authority and ample flexibility in the local implementation of the one-child policy. And starting in the early 1990s, the implementation outcome of the one-child policy was also used as a key indicator for

\footnotetext{
${ }^{8}$ Under the policy, most urban families are allowed to have only one child each. A small number of families meeting certain conditions were allowed to have a second child; the specific conditions included being parents in rural areas with only a daughter and after a specified birth gap, membership of one of the parents in an ethnic minority group, etc.
} 
the evaluation and promotion of local governmental officials (Huang, Lei and Sun, 2016). As a result, the strictness with which the one-child policy was enforced varied a great deal, potentially as a function of the differing political ambitions of the local leaders concerned.

A typical provincial regulation explicitly specified the level of the fine for the first unauthorized birth to be paid by each parent and the types of families that would be subject to such fines. Multiple fines would be levied on families that had more than one unauthorized birth. Various types of fines have been used by provincial governments in China since the early 1980s, but they all fall into one of two main categories based on the mode of payment collection: either a certain percentage of the parent's wages is deducted each month for a specified period of time, or the fine is collected as a onetime lump-sum payment. While the monthly deductions have resulted in higher collection rates, they depend on the employer's ability to collect the fines directly and are thus mostly applicable in the state sector. With the private sector playing an ever larger role in the Chinese economy, the second type of collection method has become more common as time goes by. In general, the specific amount of the fine for birth control violations depended on the parent's income. For the direct deduction method, a region would specify a range of monthly percentages (henceforth referred to as Type 1 fines), whereas, for the lump-sum payment method, either a range would be set for the total payment amount (Type 2 fines) or a multiple of the parent's annual income or the average local annual income would be used to compute the total payment (Type 3 fines). While Type 1 fines were used in most regions to begin with, the other two types gradually came into greater use, with Type 3 fines ending up being the most widely used by the early 2000 s. $^{9}$

\footnotetext{
9 A typical example of how the type of fine evolved over time is provided by the Province of Hebei, which used Type 1 fines in 1982-1988 and penalized parents for a first unauthorized birth by directly garnishing $10 \%$ of each parent's salary every month for 14 years. Starting in 1989 and continuing on until 2016, however, it switched to Type 3 fines, charging a lump-sum penalty amounting to 2.5 times the average local annual disposable income for each parent. Tibet, in contrast, maintained a Type 2 fine with a fixed amount of 3,000 RMB throughout the years from 1980 to 2006.
} 
To facilitate a comparison across regions and over time, following Ebenstein (2010), we homogenize the various types of fines relative to local income to construct the income-relative fine for each province. Specifically, for provinces using Type 3 fines, we adopt the mean value of the range as the income-relative fine, while the other two types of fines are converted as follows: For provinces using Type 1 fines, the incomerelative fine is calculated by discounting all future percentages of monthly fines at an annual rate of $2 \%$ to obtain their net present value at the start of the period during which the fine was to be levied; for provinces using Type 2 fines, the mean value of the specified range of lump-sum fines is divided by the local region's average per capita disposable income to derive the income-relative fine. In Figure 1 we present the trend over time of the average income-relative fine, which shows that the ratio has risen from 1.2 to more than 4.1 between 1980 and 2016, thereby placing a larger financial burden on the parents as time went by. Throughout the period from 1980 to 2016, there were substantial cross-regional and temporal variations in the income-relative fine, as provinces adjusted their local fine levels at different times. Most adjustments were made during the mid-1980s, the early 1990s and the early 2000s, when the central government released new guidelines for the one-child policy (as shown in Figure A1).

We explore the determinants of local fines and find no significant association with social-economic factors, except for politicians' office terms. ${ }^{10}$ Table 1 presents the results, where province and year fixed effects are controlled for and bootstrapped standard errors are clustered at the provincial level to address within-province variations of penalty fines over time. ${ }^{11}$ Column 1 shows that the estimated coefficients of key local socioeconomic factors, including local GDP per capita, wage level, and transportation availability are all insignificant. But politicians' term length, in particular, the governor's term is negatively correlated with the penalty fine. This indicates that

\footnotetext{
10 Provincial social economic variables such as GDP, population, area, cargo transportation, wage and fiscal information are from China Statistical Yearbooks. Politicians' information is from Politicians Database by Lingnan College, Zhongshan University (https://gitee.com/arlionn/IRE) and we updated the data using 2008-2017 using Baidu Baike search.

11 As shown in the table, the number of clusters is around 30, which is the number of Chinese provinces.
} 
politicians newly taking the office are more likely to choose a higher penalty fine, consistent with the theory of politicians' promotion incentives helping determine penalty fines (Huang, Lei and Zhao, 2016).

Another potential determinant of fine level is the local government's need to use it as a source of fiscal revenue, as the majority of the proceeds from these fines were kept by local governments rather than being shared with the central government. Column 2 shows that the income-relative fine level is not significantly correlated with local fiscal revenue capacity or the fiscal gap pressure. In this specification, however, the time period analyzed is shorter and thus the sample size is smaller due to missing information on the fiscal variables. As the one-child policy and the HRS land reform (1978-1984) began around the same time in China, we test whether the local penalty fine level is correlated with the land reform speed in column 3, by extending the sample period to 1981, although our main analysis focuses on the period of 1988-2001. Using the proportion of production teams enrolled in the HRS as the measure of the speed of land reform in local provinces ${ }^{12}$, we find that the HRS land reform did not significantly affect the level of penalty fines. This is in line with expectations, as the HRS land reform was largely completed in the whole nation by 1984 (Lin, 1992; Almond, Li and Zhang, 2019) while most penalty fine variations occurred in late 1980s and 1990s. In fact, the data we collected from the Provincial Gazetteers show that over 99\% of production teams in all provinces had been enrolled in the HRS by 1984 .

In addition to the fine level, fine collection rate also affects how much financial pressure the fines placed on families. It is influenced by both the mode of fine collection and the central government's overall stance toward birth control policies. Before the 1990s, as fines in most regions were deducted directly from individual's salaries, the collection rate was close to $100 \%$. When local governments switched from direct deductions to

\footnotetext{
12 The percentage of production teams enrolled in the Household Responsibility System (HRS) in each Chinese province was collected from the Provincial Gazetteers during 1979-1984, with records of Anhui, Shaanxi, Inner Mongolia, Tibet and Xinjiang missing.
} 
lump-sum fines, however, the difficulty of fine collection increased substantially. In response, the central government passed a stricter enforcement regulation in 1992, which helped maintain the collection rate at relatively high levels during the 1990s. But toward the turn of the century, while the one-child policy remained on the books, increasing concerns about potential labor shortages and about the birth rate falling to an excessively low level prompted the central government to draft the Law on Population and Family Planning in 2001 (henceforth the LPFP of 2001). For the first time, the law thus called for the protection of citizens' reproductive rights, in addition to laying down their family planning obligations, resulting in a dramatic decline in the fine collection rates (Yao, 2005; Shi, 2006). ${ }^{13}$

Local case studies have also documented similar patterns of high collection rates in the 1990s and dramatic drops after 2002 (see Figure 1). Jiang and Zhang (1993) reported that the fine collection rate in Suizhou, Hubei Province, reached an average of $91.59 \%$ during 1985-1993, and similarly high collection rates above 90\% till 2001 were also observed in Tianmen, Hubei Province, by Shi (2006). Following the passage of the LPFP of 2001, Shi (2006) found that the fine collection rate dropped abruptly to $20 \%$ in 2002 and even lower afterwards. And lower collection rates were also observed in other regions, such as $45 \%$ in Pei County, Jiangsu Province, in 2002 by Meng, Wang and Zhu (2008), 30\% in Quzhou, Zhejiang Province, in 2006 by Huang (2008), and 23.5\% in Chenzhou, Hunan Province, in 2007 by Cao (2012). Gao and Lu (2006) also provide evidence for increased difficulty in collecting birth-related fines at the local level after the passage of the LPFP in 2001. Thus, we believe that the passage of the LPFP of 2001 effectively marked the end of the strict enforcement of the one-child policy and it is therefore appropriated to use these fines to measure the stringency of the policy only in the years prior to 2002 .

\section{Data and Potential Reporting Biases}

13 This is also consistent with the drops in birth-control operations after 2002 (see Figure A2). 
We now turn to discuss the data used in the analysis and our strategy for addressing the potential reporting biases related to the data. One of the main tasks in our study is constructing a dataset of missing children in local prefectures based on family reports. To control for other factors in the analysis, we also use data on demographic and crime variables in local prefectures.

\subsection{Data on missing children}

As is true of other underground activities, there is very little information available on child abandonment and abduction, and China is no exception, with no official statistics or reports on the number of cases of child abandonment or abduction (Jiang and Sánchez-Barricarte, 2013). Following Wang et al. (2018), we use information on family-reported cases of missing children to measure child abandonment and abduction obtained from the website of Baby Come Back Home (BCBH), the largest nongovernmental organization in China serving the community of missing persons. More than $95 \%$ of these reports were filed after 2011, and 65\% were filed after 2015 (as shown in Figure 2). ${ }^{14}$

A missing person case can be logged onto the website either by a family that is looking for a missing person or by a missing person looking for his or her family. Unlike Wang et al. (2018), who also use information provided by children looking for their families, to build regional statistics for missing children, we use only the first type of data, i.e., information supplied by families looking for their children. Our reason for doing so is that, since all self-reported cases are based on recollection, missing children looking for their biological parents tend to have a vaguer memory of the location and the date of the incident and their age at the time that they went missing, as most children are quite young when abandoned or abducted and may have great difficulty providing accurate information when reporting the incident many years later.

\footnotetext{
${ }^{14} \mathrm{BCBH}$ has also collaborated with the Ministry of Public Security of China to promote the sharing of information on missing children since the Ministry launched a special operation to counter child trafficking in April 2009. Ministry of Public Security, 05/07/2009, Brief on the Anti-trafficking Special Action in China [http://www.mps.gov.cn/n2253534/n2253535/c4018254/content.html] (in Chinese).
} 
Information on a missing person can be provided to $\mathrm{BCBH}$ either online or via a hotline. Volunteers are then assigned to follow up on the reports by cross-checking the information provided with the families and the local police force, thereby minimizing false reporting. After the accuracy of the information is verified, reported cases are included in the database and listed in the forum section of the website for visitors to access and pass along. Each case report includes the name, gender, birth date, height of the child at the time he or she went missing, the location and date of the disappearance, and other descriptive information (see Figure A3). BCBH classifies missing person reports according to whether the child was deserted or given up for adoption based on the detailed descriptions provided in each case. Then each case is labeled with the status of desertion/adoption or abduction. ${ }^{15}$ In this paper, we define child abandonment as cases involving children who were either deserted or given up for adoption, i.e., cases in which families voluntarily surrendered the child. If a child was neither deserted nor given up for adoption, we classify the case as one of child abduction, i.e., in which the child was separated from the family involuntarily. ${ }^{16}$ The majority of children lost before 1990 were due to child abandonment, while the majority of children lost after 1990 were abducted (see Figure A4).

Using information given on the registration form, we geocode the longitude and latitude coordinates of the location where the child went missing. ${ }^{17}$ Geocoded locations are then matched to the administrative boundaries of the relevant prefectures. ${ }^{18}$ The age of the child at the time of missing is calculated as the difference between the year of their disappearance and their year of birth. We focus on children who were younger than 14

\footnotetext{
15 The database is publicly available at https://www.baobeihuijia.com/so.aspx (in Chinese).

16 Our categorization of child abduction is slightly broader than the legal definition of abduction, which refers to cases of children who are missing as a result of criminal action by traffickers. While there are occasional reports of parents losing a child by accident -- as, for example, when a child becomes lost in a crowd and then is not found -- such cases (cases that would not be correlated with the demand for illegal adoption, which constitutes the demand side of child abduction) are extremely rare.

17 We use the getpoint service offered by Baidu Map at http://api.map.baidu.com/lbsapi/getpoint/index.html.

18 For reports that lack detailed street locations of the incident, we use the geographic centroid of the reported prefecture for the latitude and longitude.
} 
years old at the time of their disappearance, since that is the age group identified in the official definition of child trafficking in China. From the 41,144 cases of families looking for missing persons that had been registered by June 2018, we exclude cases for which information is missing on gender, birth year, year of disappearance or addresses that cannot be used to identify prefectures, ${ }^{19}$ this leaves 40,825 cases, out of which 16,882 are child abandonment cases and 23,983 are child abduction cases. When focusing on children under 14 years old when they disappeared, we obtain 38,173 reports on missing children, which account for more than $92 \%$ of all missing person reports (see Table A1). Around 44\% of the reported cases are of children who are missing because they were abandoned, as reported by their families, whereas the remaining $56 \%$ concern families who are looking for children who were abducted or lost involuntarily.

Based on our sample, child trafficking cases exhibit some geographic clustering patterns, as shown in Figure 3. The 8 provinces for which there are the most reports of child abandonment are Sichuan, Jiangsu, Anhui, Guangdong, Henan, Hubei, Shandong and Zhejiang, which account for 53\% of all the child abandonment cases in our sample, but these 8 provinces are home to $47 \%$ of China's total population. Child abduction is even more geographically concentrated than child abandonment. The top 8 provinces reported as the location of child abductions are Guizhou, Sichuan, Guangdong, Henan, Yunnan, Hubei, Chongqing and Hunan, which account for $62 \%$ of reported child abductions in our sample but for only $38 \%$ of the total population. The destinations for trafficked children are also geographically concentrated, but in a different set of regions, which include Henan, Shandong, Hebei, Fujian, Jiangsu, Guangdong, Anhui and Sichuan. These regions are the destination for about $70 \%$ of trafficked children but account for only $47 \%$ of China's total population. ${ }^{20}$

\footnotetext{
19 Vague descriptions of the location of the disappearance are treated as missing information. Examples include "Our child got lost in front of our house", "Our child got lost on a train" and "Our child got lost in a market".

${ }^{20}$ It should be noted that the destination information may be inaccurate as it is based on the recollections of the missing child many years after the incident.
} 
The number of missing children varied substantially over time, as shown in Figure 4. There are two obvious spikes, one during the Great Famine of 1959-1962 and the other one during the early 1990s. The number of lost children remained quite stable before 1978, except during the Great Famine of 1959-1962. Starting from 1979, both child abandonment and child abduction started to increase dramatically. On average, there are 26 reports from families looking for lost children each year before 1957, but that number jumped to an average of 217 children each year between 1958 and 1962, to 212 children in 1978, and then reaching more than 2,000 missing children each year during the early 1990s. Since the mid-1990s, there has been a steep and steady decline in the number of children reported missing, with that number stabilizing since 2004, with around 385 children missing each year until 2017. Overall, more than $90 \%$ of these children were lost before 2010 , and close to $80 \%$ of the disappearances occurred before 2001. Obviously the increases observed in the last two decades of the 20th century cannot be explained by economic hardship, given the country's economic growth and the reduction in poverty achieved during that period. A more rigorous examination is needed to provide a solid explanation for the patterns of missing child incidents in China.

The two types of missing child cases, child abandonment and child abduction, differ somewhat in their time trends and in their gender and age composition. Child abandonment cases show more temporal variations. While their numbers both peaked in the early 1990s and dropped afterward, the number of child abduction cases has remained higher than its pre-1978 level after 2010, but the number of child abandonment cases has nearly returned to its pre-1978 levels. Abandoned children also tend to be much younger than abducted children at the time of their disappearance. Children who are abandoned are more likely to be newborns, whereas children who are abducted tend to be older yet still under 5 years old (see Figure 5). The gender composition of these two groups of missing children also differs. More than $70 \%$ of all abandoned children are girls, whereas about $70 \%$ of trafficked children are boys. And 
this difference in gender composition was especially stark during the period between 1978 and 2002 (see Figure 6).

\subsection{Data on gender preference}

One of the main factors that influences child trafficking is the strength of the preference for sons in the local culture. The most frequently used indicator for son preference is the sex ratio at birth (SRB) (see Ebenstein, 2010, and Chen et al., 2015). Because, under the one-child policy, Chinese families could resort to sex-selective abortions to increase the likelihood of having a son (Abrevaya, 2009; Chen et al., 2013; Oster, Chen and Yu, 2010), it is reasonable to infer that regions with higher boy-girl ratios among newborns tend to have a stronger cultural preference for boys ${ }^{21}$. In fact, whereas the average malefemale ratio for newborns is around 103:100 globally, the sex ratio at birth has remained above 110:100 in the past few decades in China. The substantially larger number of newborn boys than girls suggests a strong gender bias toward sons, whereas sexselective abortions are considered to be the main reason for this distorted gender ratio (Hull, 1990).

We use the SRB in China's population census of 2010 to reflect gender preference in local prefectures. The 2010 SRB is used for the following reasons. First of all, gender preferences are relatively stable over time. ${ }^{22}$ The mean SRB in Chinese prefectures in 2010 was 1.16 , which is much higher than in other countries and points to the important role of gender preferences in the nation's cultural tradition. The correlation between 2010 SRB and 2000 SRB is more than $90 \%{ }^{23}$ While there is substantial variation across prefectures within China, prefectures with persistently high SRBs include Huangshi, Anhui Province (1.4) and Putian, Fujian Province (1.31). Prefectures in Inner Mongolia, in contrast, continue to have relatively low SRBs, reaching a ratio of 1.02 in

\footnotetext{
${ }^{21}$ In addition to sex selective abortions, two other potential reasons leading to the excessive male-female ratio at birth are underreporting of female births (Cai and Lavely, 2003) and female infanticide (Wu, Viisainen and Hemminki, 2006).

22 As shown in Figure A3, the changes in the SRB between 2000 and 2010 indicate neither obvious convergence nor divergence at the prefecture level over that period.

${ }_{23}$ Using 2000 census data to construct the SRB measure also yields similar estimates.
} 
many prefectures. Second, as most of the missing children were lost during 1988-2001 and SRB is directly impacted by the one-child policy during the period, the 2010 SRB would serve as a relatively exogenous gender preference indicator for analyzing the relationship between missing children and penalty fines. To further test the validity of our results, we will also use sex ratio at birth from other years as robustness checks.

\subsection{Potential reporting bias}

\subsubsection{The problem of under-reporting}

Due to the self-reporting feature of the database and the unethical nature of the activities involved, our data on child abandonment and abduction suffer from under-reporting. As long as the likelihood of under-reporting is uncorrelated with the income-relative fine level, it will merely increase the measurement error in our dependent variable. Specifically, under-reporting may occur for any of three reasons. First of all, underreporting could be caused by information barriers or financial constraints faced by parents in search for their children that prevent them from reporting their missing children to BCBH. Second, families need to have survived at least until 2007, the founding year of $\mathrm{BCBH}$, in order to have been able to report their missing child on the BCBH website. Third, under-reporting may be a result of the family's lack of any intention to search for the child to begin with.

For the first type of source, we test the correlation between fine and GDP per capita or income in local prefectures in Table 1 and find that local penalty fine level is not significantly correlated with the local income. It indicates that even though richer prefectures have higher likelihood for families to report missing children due to more information access, it only brings measurement error to the number of reported cases.

As the second source of under-reporting has to do with survival bias, which is affected by the survival rate of the parents, this bias will be greater for earlier cases. According to age-specific death rate data for China, the death rate of age cohorts younger than 50 is quite stable, while the rate for people older than 50 rises sharply (Abubakar, Tillmann 
and Banerjee, 2015). Therefore, the resultant under-reporting bias will be substantially more severe for cases that occurred before 1988, since the parents would be older than 50 by 2015 . To address this potential concern, we will limit our sample to cases in which the disappearance happened after 1988. With the age-specific death rate of cohorts younger than 50 practically invariant with age in China, we argue that the problem of under-reporting due to the non-survival of parents will be largely mitigated by this strategy.

The third type of potential under-reporting bias will be very different in the case of child abandonment than in the case of child abduction. The likelihood that parents will decide to search for a missing child or not is influenced by the value of the child to the family. The more valuable a child is to his or her family, the more likely it is that the parents will devote resources to search for the child. As most abduction cases involve boys, we expect a large percentage of families to engage in a search for their abducted children, with the result that this type of under-reporting bias will less important in abduction cases. On the other hand, since child abandonment is a decision voluntarily made by the family, the likelihood of under-reporting will be higher than it will be in the case of child abduction. Therefore, there will be a greater need to address the potential underreporting of child abandonment cases in the empirical analysis. To the extent that this under-reporting is not correlated with the strictness of the one-child policy in place, it will not bias our estimates. This is likely, since a decision to search for a child who was abandoned would be the result of a change in life circumstances which, a priori, does not have to be correlated with the one-child policy.

\subsubsection{Potential misreporting of abandonment as abduction}

The dataset provides information on whether a reported case involves a child who was voluntarily given up or a child who was involuntarily separated from his or her family. We categorize the former as child abandonment and the latter as child abduction. In addition to the general issue of the under-reporting of lost or missing children, another potential problem with our data is that families may misreport an instance of child 
abandonment as child abduction, since child abandonment is still perceived as morally unethical despite how surprisingly prevalent it is in China. Misreporting a case of child abduction as child abandonment is very unlikely, however, so there is a potential upward bias in reported child abduction and an under-reporting problem for child abandonment.

Although families may misreport the reason why a child is missing, we believe that families would still accurately report other related information, such as the gender and birth year of the child and the year and location of the disappearance. As a result, the two types of biases caused by misreporting may be addressed by exploring the gender patterns of missing children. Our current statistics show that most children who are abandoned are girls. If there is misreporting of children abandonment as children abduction, then some of the girls reported as having been abducted will actually have been abandoned. It is then possible to mitigate the impact of misreporting child abandonment cases as child abduction by focusing on the sample of abduction cases involving boys only. In this way, we prevent our results concerning the relationship between the abduction of boys and the one-child policy from being affected by the misreporting problem. As for the impact of misreporting on child abandonment, as misreporting due to shame or fear of potential peer criticism is uncorrelated with the one-child policy, then, as in the case of under-reporting due to the lack of an intention to look for a missing child, it will merely increase the measurement error for child abandonment.

Based on the discussion above, the sample period for our main analysis excludes years after 2001, as the fine level can no longer measure how strict the one-child policy was enforced after the passage of the LPFP of 2001, whereas the period prior to 1988 is excluded to maintain relative stability in information access and awareness of child trafficking. Accordingly, our study focuses on the relationship between missing children and fines for the time frame of 1988-2001, but we also use the sample period of 2002-2016 as a placebo test. 


\section{Theoretical Hypotheses and Empirical Model}

\subsection{Theoretical hypotheses}

In traditional Chinese society, there is a preference for sons over daughters. In the absence of birth control policies, Chinese families would have the option of having more children until a child of the desired gender is born. Under the one-child policy, however, this option became much costlier, as hefty fines had to be paid by parents who had more than one child. This then increased the demand for the two alternatives to over-quota births, i.e., the abandonment of a first-born girl in order to retain the quota for another child, or the abduction of a boy.

Because it would give parents another opportunity to have their "first" child in the eyes of the government, the abandonment of girls became a substitute (however dreadful it may be) for giving birth to an additional child and having to pay a large fine. But more of an explanation is needed as to why the abduction of a boy -- or, equivalently, the purchase of a boy who has been abducted by others -- could also serve as a substitute for additional births. Parents who felt it extremely important to have a boy but were unwilling to give up their existing child would have to pay fines for having an additional child regardless of whether they opted to have another child themselves or to resort to having a boy abducted. The key advantage of the latter option, however, is that they are guaranteed to receive a child of the preferred gender, which is not the case if they choose to have another child of their own; hence the substitute value of boy abduction.

Thus, when the size of the fines increases, the price of having additional children rises accordingly, thereby fueling the demand for the substitute goods for additional births, i.e., the abandonment of girls or the abduction of boys. As long as the cost for the parents of abandoning a baby girl (essentially the traumatic emotional experience of separating from their own child) is not infinitely high, the supply of this substitute will be elastic and thus the stricter birth control policy will result in a larger number of baby girls being abandoned. Furthermore, in regions with a stronger-than-average preference 
for boys over girls, the supply of girl abandonment is more elastic. Thus, the same increase in birth control fines will lead to a bigger increase in the number of cases of girl abandonment in these regions. In the case of boy abduction, as long as there is uncertainty as to the gender of a future naturally born child, the increased fine and thus the higher price of additional births will drive up the demand for abducted boys. Additionally, in regions with a stronger-than-average preference for boys over girls, the same increase in birth control fines will lead to a bigger increase in the demand for abducted boys, since their gender (the desired one) is known. Thus, in parallel with the dynamics observed in the case of girl abandonment, the same increase in birth control fines will lead to a bigger increase in the number of boy abductions in these regions.

\subsection{Empirical model}

Taking advantage of regional and temporal variations in birth control policies, we will then empirically test the theoretical hypotheses outlined above. In particular, we will estimate the average effect of changes in income-relative fines on the number of cases of child abandonment and child abduction, along with the heterogeneity of such effects due to differences in gender preferences across Chinese regions.

Although penalties for violating the one-child policy also included other measures, such as demotion, deprivation of promotion opportunities, restrictions on eligibility for the hukou family registration program and the loss of other social benefits, we focus on the fines as a measurement of the stringency of the one-child policy because it is the policy component that is most widely used and for which the most information is readily available. We use the following empirical model to estimate the impacts of fines on missing children:

$$
\mathrm{Y}_{i t}=\alpha \mathrm{F}_{i t}+\beta \mathrm{X}_{i t}+\mu_{i}+\lambda_{t}+\rho_{i} \mathrm{t}+\varepsilon_{i t}
$$

where the dependent variable, $\mathrm{Y}_{i t}$, is the quantity of child abandonment or abduction in prefecture $\mathrm{i}$ in year $\mathrm{t}, \mathrm{F}_{i t}$ is a vector of fine variables, including local fines and fines 
in other regions, while $\mathrm{X}_{i t}$ is a set of control variables that includes local population density, total number of arrests in the local region, which reflects both the crime rate and the strength of the policing effort, as well as terms and ages of provincial leaders (including the party secretary and governor of each province). Prefecture fixed effects are included to control for unobservable cross-prefecture variations that do not vary over time, such as regional variations in the preferences for males, family size preferences and the local culture's level of tolerance of unethical activities. Year fixed effects are included to control for variations that are the same across prefectures, such as national trends in child trafficking and other crimes. Furthermore, prefecture-specific trends are included to control for time-varying factors that take a linear form at the prefectural level, such as regional anti-trafficking efforts, and local variations in media and transportation infrastructure. Standard errors are clustered at the prefecture level to correct the within-prefecture correlation of the error term.

Because child abduction is an inter-regional, underground business, penalties in the form of fines may not only affect child trafficking in the local prefecture but also child abduction in other prefectures. To better distinguish the effects of the fines levied in different regions, we explore the spatial impacts in two different ways. Firstly, we focus on the immediate neighboring provinces or the 1st-order provincial neighbors of the local prefecture, by constructing their population weighted fine level, since crossprovincial trafficking cost is much higher than within-province trafficking (Wang et al., 2018). By exploring whether the average fine level in the 1st-order neighbors affects the number of missing children in a prefecture, we can identify the existence of spatial spillover effects since penalty fines are determined at the provincial level. Alternatively, we explore more gradual spatial changes and classify all other prefectures based on their geographic distances to the local prefecture into the following categories: those that are $0-300 \mathrm{~km}, 300-600 \mathrm{~km}, 600-900 \mathrm{~km}$ and further than $900 \mathrm{~km}$ away from the prefecture. The size of the fine in each group of prefectures is then calculated as the population-weighted average fine in the same distance group in order to reflect the relative stringency of the enforcement of the one-child policy in these regions. 
In order to identify how local gender preference affects the impact of the one-child policy on child trafficking, we include two types of interactions between the size of the fine and the sex ratio at birth (SRB) in the estimations: local fine and local SRB, and the average fine and the average SRB of neighboring regions, as shown in Equation (2) below:

$$
\mathrm{Y}_{i t}=\alpha \mathrm{F}_{i t}+\alpha_{2}\left(\mathrm{~F}_{i t} * \mathrm{SRB}_{i}\right)+\beta \mathrm{X}_{i t}+\mu_{i}+\lambda_{t}+\rho_{i} \mathrm{t}+\varepsilon_{i t}
$$

Given that child abandonment is mainly the result of decisions made by families in the local region, the coefficient of the interaction of local fine and local SRB is expected to be positive for abandonment. Moreover, because girls are more likely to be abandoned than boys, the increase in child abandonment should be higher for regions with a stronger preference for males. By comparison, the level of child abductions is mainly influenced by the gender preferences of the neighboring regions that are subject to the one-child quota because child traffickers tend to find destination households some distance away from the original location of the missing child in order to avoid being caught. Specifically, we use a discrete variable of a high-SRB group, with the 2010 SRB above 1.17 (the national average SRB level in 2010) to reflect regional variations in gender preference. As a robustness check, we also explore the interactions of fine variables with the continuous measurement of SRB as well as SRB measures from other years.

\section{Results}

\subsection{Fines and child abandonment}

We find that higher penalty fines lead to significant increases in child abandonment in the local prefecture. Table 2 presents the estimated coefficients for fines and child abandonment using regression model (1) for the period of 1988-2001. Column 1 shows that, when the fine level increases by one unit or, in other words, the monetary penalty is increased by the equivalent of the per capita average annual local income, the number 
of reported cases of child abandonment increases by 0.3 in the local prefecture. Given that the average number of reported cases of child abandonment is 2.15 per year at the prefectural level, such an increase in the fine corresponds to a raise of around $14 \%$ in reported cases of child abandonment. The impact of the fines on child abandonment is significant only for girls, as shown in columns 2 and 3 of Table 2. Girl abandonment increases by 0.25 or a $14.9 \%$, when the income-relative fine increases by 1 . The abandonment of boys is not significantly affected by the local fine, although the coefficient is positive. Given the restricted birth quota and the preference for sons in the Chinese culture, parents will have an incentive to abandon girls for the purpose of avoiding the fines and saving their birth quota for a potential boy in the future. And the more stringent the enforcement of the birth control policy, the more likely girls are to be abandoned by their families. The above results support our theoretical predictions.

The results show that larger fines lead to an increase in child abandonment only in the same local prefecture, whereas the coefficients for average fines in neighboring provinces relative to child abandonment are not statistically significant (see column 4). ${ }^{24}$ As expected, we do not observe spatial spillover effects of the fines on child abandonment in other regions, and the pattern is similar for the abandonment of both boys and girls. Because the main effect of higher fines is to increase the financial cost of violating the one-child policy, child abandonment, which is the result of a decision made by the parents of the abandoned child themselves, is only affected by the stringency of the local one-child policy and should not be affected by the stringency of its enforcement in other regions.

Among the control variables, neither population density nor law enforcement affect the number of reported child abandonment cases significantly, probably because child abandonment was not severely punished in China before 2001, although it was legally

\footnotetext{
24 The standard errors in the specification reported in column 4 of Table 2 are clustered at the provinceyear level, as there might be positive correlations in the error term in prefectures within the same province in a certain year due to similar culture of child abandonment, close communications and other similarities.
} 
defined as a crime. This finding is also consistent with the voluntary nature of child abandonment, since this suggests that it is not correlated with typical crime or environmental factors, such as population density and the crime rate. We do find significant correlations between the governor's term with the number of total child abandonment and girl abandonment. This is consistent with the theory of politician promotion incentives in that politicians try to improve local governance and overall social conditions in the early terms of their office to impress the upper level evaluators.

Finally, the positive and significant coefficient of local fine remains when we remove all control variables and when we replace the prefectural trends with provincial trends, as shown in columns 5 and 6 .

\subsection{Fines and child abduction}

Child abduction differs from child abandonment in China in two ways. First, the destination of children who are abducted tends to be more distant from the location of the abduction, as child traffickers travel afar to avoid recognition by the parents and capture by the police. Second, most of the children abducted in China are boys, whereas most of the children abandoned are girls.

Table 3 presents the estimated coefficients for fines and child abductions. In contrast to the findings for child abandonment and in line with the above discussion, the number of children who are abducted is significantly influenced by the size of the fine in nearby provinces but not by its size in the local region. When the population-weighted fine in neighboring provinces increases by one unit, there is 1 more reported case of child abduction, which amounts to about $35.7 \%$ of the total number of cases of child abduction in the local prefecture (see column 1). Given that almost all provinces increased the stringency of their enforcement of the one-child policy by raising local fines and that the policy compliance rate remained high between 1988 and 2001, the positive coefficient that we observe helps to explain the sharp increase in child abductions during that period in China. 
As a majority of the children abducted are boys, we find that the size of the fines has a significant effect only on the number of boys who were abducted, as shown in columns 2 and 3. The number of missing boys due to abduction increases by 0.89 or $43.4 \%$ of the average level when neighbors' penalty fine increase by 1 unit; but we do not find similar patterns in the case of girls. This is consistent with the theoretical argument that a stricter enforcement of the birth control policy would drive up the demand for boys, making it more lucrative for traffickers to abduct boys. Anecdotal evidence also indicates that the cost of adopting a boy is much higher than the cost of adopting a girl (Shen, Antonopoulos and Papanicolaou, 2013). In contrast to the upward pressure exerted by local fines on the abandonment of girls, the effect of fines in terms of the abduction of boys is significant only in nearby prefectures, i.e., prefectures located in the local region's first-order neighboring provinces (see column 2). This is in line with the expectation that child traffickers attempt to evade capture by taking the abducted children further away from the abduction site.

Among the control variables, the coefficient of population density is positive and close to being significant (at 5\% level), while the coefficient of local arrests is negative and insignificant. This indicates that the probability that a child, especially a boy, being abducted is higher in more densely populated regions and lower in regions with stricter law enforcement. As it is crucial for offenders who abduct a child to avoid being apprehended, the cost of abducting a child is expected to be lower in more densely populated regions and where law enforcement is laxer. Local politicians' characteristics are not significant here although the provincial secretary's term is negatively correlated with the number of children abducted, suggesting that cross-regional illegal child trafficking activities might be difficult to be constrained by efforts in one local prefecture. Our estimates of the positive impacts of neighbor's fines on child abduction remain robust when we cluster standard errors at the province-year level, remove all controls or replace prefectural trends with province trends, as shown in columns 4-6. 


\subsection{Spatial patterns of child abandonment and child abduction}

We explore the geographic spread of the birth control policy's impact further in this section by using more detailed distance information instead of neighboring relationship of administrative provinces. This is particularly relevant for child abduction cases, as longer trafficking distances would increase the transportation cost and exposure risk for traffickers while reducing their risk of being discovered by the children's families or by local police. Child traffickers therefore have an incentive to choose a destination located at an intermediate distance in order to minimize the total cost of their operation. And in fact, previous research on child abduction has found that children are primarily trafficked to neighboring provinces and places within $500 \mathrm{~km}$ from the location of the abduction (Wang et al., 2018).

To examine the geographic patterns empirically, for each local prefecture we assign all other prefectures to one of four groups based on their geographic distance from the local prefecture: those within $300 \mathrm{~km}, 300-600 \mathrm{~km}$, or $600-900 \mathrm{~km}$ from the prefecture and those further than $900 \mathrm{~km}$ away from it. Then, for each prefecture group, we construct the average fine levied in all the prefectures in the same group using their respective populations as weights. Figure 7 presents the estimated coefficients and their $95 \%$ confident intervals of the population-weighted average fine in each distance group on child abandonment and child abduction (see Table A2 for more detailed information). Consistent with the above results, child abandonment, which mostly involves girls, is positively influenced only by the size of the locally levied fine, whereas the coefficients for fines in all four groups of non-local prefectures are not significantly different from zero for child abandonment. In contrast, child abduction is significantly influenced by the size of the fines levied in prefectures located between 300 and $600 \mathrm{~km}$ away, or from 3 to 6 hours' driving distance from the local prefecture, while the coefficients for the fines in the local prefecture and other groups of non-local prefectures are not significant. This confirms the previous finding that most children trafficked are taken to destinations within $500 \mathrm{~km}$ of their abduction site (Wang et al., 2018). As larger fines increase the demand for child adoption and thus the value of children who are abducted, 
the spatial spillover effects of fines on child abduction point to the widespread geographic impact of birth control policies on child trafficking.

\subsection{Gender preferences, fines and missing children}

As predicted in Section 4.1, gender preferences play an important role in determining the impacts of the one-child policy. Table 4 presents the estimated coefficients in equation (2), including interactions of fine variables and the indicator variable for whether a region has high SRB in 2010 or not as the gender preference intensity measure. The coefficient of the interaction between local fine and local high SRB indicator is positive and significant for all abandonment and girl abandonment, as shown in columns 1-2. The results indicate that the impact of the fine on child abandonment is significantly higher in regions with a stronger gender bias. The interaction impact of penalty fine and gender bias preference is especially true for girl abandonment. Prefectures with stronger preference for boys are more likely to see increased abandonment of girls by families wishing to keep the birth quota so that they can potentially have another baby in the future. As shown in columns 3 and 4, when the interactions of neighbor fine and neighbor's high SRB status are included, the positive coefficients of interactions between local fine and high SRB status remain robust. And the results are preserved when we use interactions of fine variables with the continuous SRB measure instead of discrete indicators (as shown in Table A3).

In contrast to the situation with regard to child abandonment, the level of child abduction is significantly influenced by the fine level in neighboring provinces, and thus we include the interaction between the immediate neighbors' average fine and those regions' overall SRB in the estimation in order to study the impact of gender preferences. As shown in columns 5-8 of Table 4, the coefficient for the interaction of the fine and high SRB status in the neighboring regions is positive while being borderline significant at the $10 \%$ level for all child abduction. For boy abduction, the coefficient of neighbors' fine and neighbors' high SRB status is positively significant. The results indicate that a larger increase in the number of boy abduction cases will be 
observed in a prefecture when birth control fines in its neighboring provinces are higher if those provinces also have a stronger gender bias toward boys. In contrast to child abandonment, the interactions of local fine and local high SRB status are not significant when included in columns 7 and 8. This indicates that local fine and local gender perception bias do not significantly affect boy abduction, consistent with the distant abduction pattern in our results on how fines affect child abduction. The results remain when we use the continuous measure of SRB, as shown in Table A4.

\subsection{Missing children in different age groups}

Unlike the case in other countries, the main purpose of child trafficking in China is to put the children up for illegal adoption to get around the birth control policy. This offers another dimension in which we can conduct additional tests for the argument that birth control policies have been a reason for why children go missing in China. In particular, we explore the age patterns of children abandoned and abducted and how their age frequency has been impacted by changes in birth control policy.

While we focus on the intention to keep the birth quota for a chance of having a boy in the future as the main reason for girl abandonment, researchers have also documented cases where some families abandon children with disabilities or severe diseases. If the parents' decision to abandon a child is mainly driven by changes in the one-child policy, then families would abandon children at very early ages in order to avoid official checks. But if the latter reason is the main one, then the age at abandonment will spread over a wider range. Figure 8 presents the estimated coefficients and their $95 \%$ confidence intervals for fines' effects on the number of child abandonment and abduction in five age groups: 0, 1, 2-4, 5-9 and 10-14 (see detailed results in Table A4). The results show that fines significantly and positively influence child abandonment only for newborns (babies younger than 1 year of age), while the abandonment of children in any of the other age groups is not significantly affected by the size of the fines. The result thus supports our argument that families abandon their children (mainly girls) to avoid fines in preparation for a future birth. 
In contrast, we find that stricter enforcement of the one-child policy mainly increases the number of abductions of children between 1 and 4 years old. When neighboring provinces increase the average fine by 1 , the number of 1 -year-old children abducted would increase by 0.22 and the number of abducted children between 2 and 4 years of age would increase by 0.80 . The level of the average fine in neighboring provinces did not, however, significantly impact the number of abducted children who are either younger than 1 or older than 5 . While younger children are preferred for illegal adoptions because of their limited early memory and attachment to their biological parents, newborns are usually kept indoors and accompanied by adults almost all of the time, making them much less accessible to child traffickers. As a result, children between the ages of 1 and 4 are the primary target of child traffickers, since they are still malleable enough to form new memories with their adoptive families and also are engaged in more outdoor activities and are thus more accessible. These findings are therefore consistent with our argument concerning birth control policies' impact on the number of missing children.

\subsection{Placebo test: missing children after 2002}

Although the one-child policy was not officially abolished until 2016, when it was replaced by the two-child policy, the enforcement of the one-child policy was eased a great deal after the passage of the Law on Population and Family Planning (LPFP) in 2001 in response to mounting criticism of the harsh measures adopted by local officials to meet their birth control targets, including forced abortions performed during latestage pregnancies. The LPFP emphasizes that individuals' reproductive rights should be respected and mandates civilized law enforcement responses to violations of the onechild policy. Local governments are also required to use economic incentives and other more civilized approaches in order to meet local birth control targets. As a result, the enforcement of the one-child policy has been relaxed substantially after 2002. Under the LPFP, forced abortions are no longer permitted, and fines for having an additional child can no longer be collected using force. Several researchers have documented a 
significant drop in the collection rate for these fines since the early 2000s (Shi, 2006, and Gao and $\mathrm{Lu}, 2006)$. The passage of LPFP has thus been regarded as the main reason for the gradually relaxation of the one-child policy since 2001 .

Without the effective collection of birth control fines, the link between the size of the fine and the number of missing children ceases to exist. Thus, the sample for the period after 2002 can be used as a placebo test of the argument linking the one-child policy and missing children. Specifically, we analyze the impact of the fines on child abandonment and child abduction in 2002-2016, with the estimation results shown in Table 5. As expected, most of the fine variables do not significantly affect either child abandonment or child abduction. ${ }^{25}$ In other words, neither the size of child abandonment nor that of child abduction changes significantly in response to changes in fine level after 2002. Furthermore, the number of reported cases of children abandonment dropped dramatically, to around 46 cases per year on average, during 2012-2015, suggesting that families became more likely to keep their unauthorized children after 2002.

Given that no obvious changes have occurred in gender preferences in the past two decades, the demand for male heirs appears to have remained more or less the same. Therefore, the different patterns observed before and after 2002 provide further support for the proposition that it is the strict enforcement of the one-child policy that provides an explanation for the higher incidence of child abandonment and child abduction during the last two decades of the 20th century in China.

\subsection{Robustness checks}

We test the robustness of our main findings by conducting additional tests, with the results shown in Table 6 . To begin with, we replace the dependent variable used in the

\footnotetext{
25 The only significant result is the negative coefficient of local fine on boy abandonment. As the number of boy abandonment cases is quite small in the overall child abandonment sample, the significance is most likely driven by spurious correlation with a few observations of boy abandonment taking the nonzero value.
} 
previous estimations, i.e., the total quantity of child abandonment and abduction, with the logarithm of child abandonment and abduction, so that the coefficients can be interpreted as the percentage change in the number of missing children. Column 1 shows that our results remain robust, indicating that the existence of fines significantly increases the incidence of child abandonment and abduction, whether measured in terms of absolute levels or percentage changes.

One concern with regard to our main results is that zeros have been assigned to observations (prefecture-year pairs) in which there are no reports of missing children. This could be seen as a problem of data censoring, because zero values may represent either observations with no children missing or under-reporting in cases with missing children. We address this potential problem by estimating a Tobit model that takes into account of the left-censoring feature of child abandonment and child abduction measurements. We use the generalized panel Tobit model proposed by Honoré (1992) to estimate the coefficients of the fines and report the results in column 2 of Table 6 . The coefficient of local fine for child abandonment remains significant and the coefficient of neighbors' fine for child abduction is positive and significant at the $89 \%$ confidence level, indicating that our findings remain robust to addressing this potential nuisance.

Since capital cities tend to have larger populations and larger population flows, there are more cases of missing children in those cities. We exclude provincial capital cities from the sample and obtain largely similar results (as shown in column 3 ). As the onechild policy was implemented less strictly in ethnic minority regions, in one specification we exclude the five autonomous provinces that have large ethnic minority populations and again obtain robust results (see column 4$){ }^{26}$

Our results are also largely robust to the inclusion of both linear and nonlinear

${ }^{26}$ These five regions are Inner Mongolia, Ningxia, Guangxi, Xinjiang and Tibet. 
prefectural trends (see column 5), as well as to the inclusion of additional control variables (see column 6), such as GDP per capita (in logarithms) and the number of children under 5 years of age in the prefecture. The results indicate that the coefficients of fine payment variables are quite similar to the main results given in Tables 2 and 3, despite the fact that the number of observations drops by close to $30 \%$ due to missing GDP information for some prefectures. Overall, the effects of the fines on child abandonment and child abduction remain robust.

As mentioned previously, there is also the concern of misreporting child abandonment as child abduction. Given the general pattern of the abandonment of girls and the abduction of boys, the misreporting of child abandonment as child abduction, if any, is more likely to concern girls. Thus, we construct a pseudo abandonment variable as the sum of total abandonment plus girl abduction. As shown in column 7, our results remain robust to using this new sample, which implies that the misreporting problem is not a problem.

Another potential confounding factor affecting the patterns of missing children is the availability of prenatal sex selection technologies, as they may substitute for post-birth measures for obtaining children of the preferred sex. We address this issue in column 8 by using the sample data for 1990-2001 instead of 1988-2001, as the diagnostic ultrasound technology had been introduced to practically all Chinese counties by 1990 (Chen, Li and Meng, 2013). Our results remain robust, indicating that the penalty fine of the one-child policy has caused increases in child abandonment and abduction even when families already had access to pre-birth gender selection technologies.

\subsection{Separating rural versus non-rural samples}

To further address the concern regarding how the access to sex-selective abortions in local families would affect the impact of fines on missing children, we explore the potential effects of the HRS land reform next. Because child abandonment and abduction are also family behaviors related to sex selection, the pre-birth sex selection 
might substitute for post-birth gender selection. Following the argument that rural families had relatively less access to pre-birth sex selective abortions than urban families (Almond, Li and Zhang, 2019), we classify all reported cases into rural and non-rural categories based on the reported location where the child went missing. A case is classified as rural if the reported location has the keyword of "village" and nonrural otherwise. And more than $70 \%$ of child abandonment and abduction cases in our sample were reported to have occurred in non-rural areas.

Table 7 lists the regression results of fines on child abandonment and abduction in rural and non-rural areas separately. It shows that the positive effects of local fine on child abandonment and positive impacts of neighbors' fine on child abduction are significant in both rural and non-rural regions, with the effects in non-rural areas slightly larger than rural areas but the difference being statistically insignificant. This indicates that even though the non-rural areas may have better access to prenatal sex selection, families still resort to the post-birth sex selection approach of child abandonment and abduction to achieve the desired gender ratio among children. In addition, as non-rural regions are less likely to be affected by the HRS land reform, these results also help mitigate the confounding impact of the land reform on child abandonment and abduction, providing additional support for the independent effect of the one-child policy.

\subsection{Checking data validity using the Great Famine (1959-1961) event}

As discussed earlier, the impact of the one-child policy on the number of missing children is mainly attributable to the additional financial burden faced by families of having to pay fines for having another child. Studies have also shown that the number of missing children has tended to increase during or after major natural disasters (Shen, Antonopoulos and Papanicolaou, 2013). One explanation is that severe disasters often

lead to decreases in household income and food availability, driving up the cost of raising a child and hence the likelihood of abandonment. In addition, the amount of care that families give their children also tends to decrease in such situations due to the 
ensuing chaos. As a result, children are more likely to go missing either because they are abandoned or abducted.

If the reports of missing children in the $\mathrm{BCBH}$ database provide a representative sample of the actual number of missing children in Chinese regions over time, then we would expect to see a larger number of missing children during the Great Famine of 19591961, when many Chinese provinces experienced severe famines caused by crop failures, and a large part of the country saw its population shrink due to starvation and food-shortage-induced mortality (Mu and Zhang, 2011; Meng, Qian and Yared, 2015).

We check for this pattern by studying the relationship between the number of missing children and the intensity of the impact of the Great Famine across Chinese regions. Table 8 presents the regression results for the impact of provincial death rates (Meng, Qian and Yared, 2015) on the number of missing child cases in each province using the BCBH data for 1950-1970. Column 1 shows that a higher death rate is significantly and positively correlated with the total number of children reported missing. According to Meng, Qian and Yared (2015), the death rate increased from 10.6 per 1,000 in 1957 to 15 per 1,000 in 1959 and then to 23 per 1,000 in 1960. Thus, our estimates imply that the total number of missing children increased by around 9.1 per 1,000 from 1957 to 1960, which accounts for $277 \%$ of the average annual level. Column 2 reflects a positive correlation for missing boys, while column 3 reports a positive association for missing girls. Thus, for both boys and girls, there was a higher probability that they would be separated from their families during the famine years. Columns 4 and 5 further show that both child abandonment and child abduction were positively correlated with the severity of the Great Famine at the provincial level. Columns 6-10 present similar patterns when the death rate is replaced by the Great Famine dummy, which takes a value of 1 for the years from 1959 to 1961 . These patterns thus help to corroborate the quality of the $\mathrm{BCBH}$ database.

\section{Conclusion}


Child trafficking has been a major underground economic activity globally and economic hardship faced by families has been attributed as a main determinant. However, against a backdrop of rapid economic growth, China experienced a sharp increase in child abandonment and child abduction in the 1980s and 1990s. We argue that the combination of the one-child policy and the cultural preference for sons is the main explanation for the large numbers of child abandonment and child abduction cases during those years. The combination of these two factors has also shaped the unique gender composition of child trafficking in China, where most of the children abandoned are girls and most of the children abducted are boys.

Our empirical analysis relies on two sets of data: the family-reported missing child cases filed on the website of Baby Come Back Home $(\mathrm{BCBH})$, the largest online platform for posting information on missing children, are used to construct the dataset on missing children for each prefecture in all years from 1979 to 2018; and variations in the strictness of the one-child policy in local provinces are measured at the provincial level by the income-relative fine for the first unauthorized birth. Based on empirical case studies and statistics on birth control operations and fee collection rates, we then divide the period during which the one-child policy was in effect into two sub-periods: 1979-2001, when the policy was more strictly enforced, and 2002-2016, when it was applied less stringently. To address the potential problem of underreporting, we further limit the period of our main analysis to the years after 1988 .

During the stringent policy enforcement period, higher fines are found to significantly increase child abandonment. When the per parent fine amount increased by the amount of average local per capita annual income, the number of child abandonment cases increased by 0.3 , which is equivalent to a $14 \%$ increase in the average annual number of abandonment cases. The impact of the fines in driving up the rate of child abandonment is confined to cases involving girls, which is consistent with the general preference for sons in China. Higher fines increase the number of cases of abandonment of girls in the local prefecture and have no spillover effects on other regions. In contrast, 
increases in fines lead to a significant increase in child abductions in neighboring provinces; the impact of such increases is confined to abduction cases involving boys, with increases in those fines having no significant impact on the abduction of girls either in the local region or other regions. When the per parent fine amount increases by the local average annual per capita income, the number of children abducted from neighboring provinces increases by 1 , which is equivalent to a $35.7 \%$ increase over the average level.

The cultural preference for sons heightens both the local impact of the fines on the abandonment of girls and the spillover effect on the abduction of boys. Child abandonment in regions with a stronger preference for sons increases more sharply in response to increases in the fines. By the same token, fine increases in regions with a stronger cultural bias towards sons trigger larger spillover effects on the abduction of boys in neighboring regions. Furthermore, we find that geographic distance explains much of the spatial spillover effects regarding the abduction of boys. Overall, we find that the impact of these fines on child abandonment is the largest in the case of newborns while the spillover effect of the fines on child abduction is the strongest in the case of children from 1 to 4 years old.

Importantly, our results are not confounded by two other policies that may also impact families' decisions regarding child abandonment and abduction, the implementation of the HRS land-reform policy and the availability of pre-natal sex-selection technologies. Although the HRS policy started at about the same time as the one-child policy in China, the nation-wide land reform was completed by 1984. Thus, by using data from 19882001, our study focuses on a time period when the one-child policy was implemented independently from the land reform policy. Furthermore, we find that the positive effects of penalty fines on child abandonment and abduction are of similar size in both rural and non-rural areas, whereas the effects of land reform should only be observed in rural regions. 
Similarly, as pre-natal sex-selection technologies had become widely available through Chinese counties by 1990 (Chen, Li and Meng, 2013), there was little variation in their availability in much of our sample period of 1988-2001, implying little explanatory power for such technologies in accounting for child abduction and abandonment. Furthermore, limiting the sample to 1990-2001 preserves our findings and dividing the rural and non-rural regions (where the availability of pre-natal sex-selection technologies may differ) shows no significant difference in the results for the two subsamples, both bolstering the one-child policy explanation of missing children instead of the pre-natal sex-selection story.

To our knowledge, this is the first study to explore the institutional reasons behind missing children in China, where the combination of the one-child policy and a cultural preference for sons has shaped the unique gender pattern of child abandonment and child abduction practices. By focusing on families' decisions on child abandonment and abduction, or post-birth sex selection, our study supplements the current literature about prenatal sex selection family decisions. While the application of pre-natal sex-selection technologies has led to a large number of missing women in India and China, child abandonment and abduction may have long lasting impact on the education, income and life quality of surviving individuals. Furthermore, our study identifies an additional unintended consequence of the one-child policy, thereby contributing to the analysis of the impacts of the largest-ever fertility control policy in human history. 


\section{References}

Abrevaya, J. (2009). Are There Missing Girls in the United States? Evidence on Gender Preference and Gender Selection. American Economic Journal: Applied Economics, 1(2): 1-34.

Abubakar, I. I., Tillmann, T., \& Banerjee, A. (2015). Global, regional, and national agesex specific all-cause and cause-specific mortality for 240 causes of death, 1990-2013: a systematic analysis for the Global Burden of Disease Study 2013. Lancet, 385(9963), 117-171.

Alesina, A., Giuliano, P., and Nunn, N. (2013). On the Origins of Gender Roles: Women and the Plough. Quarterly Journal of Economics, 128(2): 469-530.

Alesina, A., Giuliano, P., and Nunn, N. (2018). Traditional Agricultural Practices and the Sex Ratio Today. PloS One, 13(1): e0190510.

Almond, D., Li, H., and Zhang, S. (2019). Land Reform and Sex Selection in China. Journal of Political Economy, 127(2): 560-585.

Anderson, S., and Ray, D. (2010). Missing Women: Age and Disease. Review of Economic Studies, 77: 1262-1300.

Bhalotra, S., Chakravarty, A., Mookherjee, D., and Pino, F.J. (2019). Property Rights and Gender Bias: Evidence from Land Reform in West Bengal. American Economic Journal: Applied Economics, 11(2): 205-237.

Cai, Y., Lavaly, W. (2003). China's Missing Girls: Numerical Estimates and Effects on Population Growth, China Review, 3(2): 13-29.

Cao, B. (2012). Study on Administration of Collecting Social Maintenance Fee under Family Planning: Example of Suxian District in Chenzhou. Journal of Hunan University of Finance and Economics, 28(06): 28-33.

Chen, Y., Ebenstein, A., Edlund, L., and Li, H. (2015). Girl Adoption in China: A Lessknown Side of Son Preference. Population Studies, 69(2): 161-178.

Chen Y., Li, H., and Meng, L. (2013). Prenatal Sex Selection and Missing Girls in China: Evidence from the Diffusion of Diagnostic Ultrasound. Journal of Human Resources, 48(1): 36-70.

Corno, L., and Voena, A. (2019). Selling Daughters: Age of Marriage, Income Shocks 
and the Bride Price Tradition. IFS Working Paper W16/08.

Dahl, G., and Moretti, E. (2008). The Demand for Sons. Review of Economic Studies, 75: 1085-1120.

Dessy, S., Mbiekop, F., and Pallage, S. (2005). The Economics of Child Trafficking (part ii). Cahier de recherche/Working Paper, 05-09.

Ebenstein, A. (2010). The "Missing Girls" of China and the Unintended Consequences of the One Child Policy. Journal of Human Resources, 45(1): 87-115.

Edlund, L., Yi, J., Li, H., and Zhang, J. (2013). Sex Ratio and Crime: Evidence from China. Review of Economics and Statistics, 95(5): 1520-1534.

Gao, J., and Lu, Y. (2006). Study on Social Upbringing Fee Collection in Dezhou, Shandong Province. Population \& Economics, 2006(2): 17-22.

Hesketh, T., and Xing, Z.W. (2006). Abnormal Sex Ratios in Human Populations: Causes and Consequences. Proceedings of the National Academy of Sciences, 103(36): $13271-13275$.

Honoré, B. E. (1992). Trimmed Lad and Least Squares Estimation of Truncated and Censored Regression Models with Fixed Effects. Econometrica, 60(3): 533-565.

Howden, D., and Zhou, Y. (2014). China's One-Child Policy: Some Unintended Consequences. Economic Affairs, 34(3): 353-369.

Huang, W., Lei, X., and Sun, A. (2016). When Fewer Means More: Impact of OneChild Policy on Education of Girls. IZA Working paper.

Huang, W., Lei, X. and Zhao, Y. (2016). One-child Policy and the Rise of Man-made Twins. Review of Economics and Statistics, 98(3): 467-476.

Huang, Y. (2008). The Problems of Social Maintenance Fees: Example of Leqing. Population and Family Planning (in Chinese), 2008(07):28-29

Hull, T. H. (1990). Recent Trends in Sex Ratios at Birth in China. Population and Development Review, 16(1), 63-83.

International Labour Organization (2017). Global Estimates of Modern Slavery: Forced Labour and Forced Marriage.

Jayachandran, S. (2017). Fertility Decline and Missing Women. American Economic Journal: Applied Economics, 9(1), 118-39. 
Jayachandran, S., \& Kuziemko, I. (2011). Why do Mothers Breastfeed Girls Less Than Boys? Evidence and Implications for Child Health in India. The Quarterly Journal of Economics, 126(3), 1485-1538.

Jiang, Q., and Sánchez-Barricarte, J. (2013). Child Trafficking in China. China Report, 49(3), 317-335.

Jiang, G. and Zhang, Q. (1993). Approaches to Enhance the Management of Penalty Fines on Unauthorized Births in Suizhou. Fiscal Accounting Communication (in Chinese), 1993(08):45

Johnson, K., Huang B., and Wang L. (1998). Infant Abandonment and Adoption in China. Population and Development Review, 24(3): 469-510.

Li, C., Ren, R., and Zhang, X. (2013). The Current Condition of Child Trafficking and Child Protection in China: Empirical Analysis Based on 133 Public Cases. Journal of People's Public Security University of China (Social Science Edition), 29(6): 16-25.

Lin, J. Y. (1992). Rural Reforms and Agricultural Growth in China. The American Economic Review, 34-51.

Liu, J., Larsen, U., and Wyshak, G. (2004). Factors Affecting Adoption in China, 195087. Population Studies, 58(1), 21-36.

Meng, X., Qian, N., and Yared, P. (2015). The Institutional Causes of China's Great Famine, 1959-1961. Review of Economic Studies, 82(4): 1568-1611.

Meng, H., Wang, G. and Zhu, X. (2008). Approaches to Raise the Collection Rate of Social Maintenance Fees in Pei County. Journal of Nanjing College for Population Program Management (in Chinese), 2008(01): 33-37

Mu, R., and Zhang, X. (2011). Why Does the Great Chinese Famine Affect the Male and Female Survivors Differently? Mortality Selection Versus Son Preference. Economics \& Human Biology, 9(1): 92-105.

O’Connell Davidson, J. (2011). Moving Children? Child Trafficking, Child Migration, and Child Rights. Critical Social Policy, 31(3): 454-477.

Oster, E., Chen, G., and Yu, X. (2010). Hepatitis B Does Not Explain Male-Biased Sex Ratios in China. Economics Letters, 107(2): 142-144.

Qian, N. (2008). Missing Women and the Price of Tea in China: The Effect of Sex- 
Specific Income on Sex Imbalance. Quarterly Journal of Economics, 123(3): 12511285 .

Scharping, T. (2013). Birth Control in China 1949-2000: Population Policy and Demographic Development, Routledge.

Sen, A. (1990). More than 100 Million Women are Missing. The New York Review of Books, 37(20), 61-66.

Shen, A., Antonopoulos, G. A., and Papanicolaou, G. (2013). China's Stolen Children: Internal Child Trafficking in the People's Republic of China. Trends in Organized Crime, 16(1): 31-48.

Shi, D. (2006). Study on Reasons Why It Is Difficult to Collect Social Upbringing Fee. Market \& Demographic Analysis, 2006(2): 78-80.

Tamura, Y. (2010). Migrant Smuggling. Journal of Public Economics, 94(7-8): 540548.

Tao, L. (2017). Prevention and Characteristics of Child Trafficking Based on 200 Sentencing Documents. Youth and Adolescent Studies, 2017(5): 19-24.

The State Council (2011). Action for Child Development in China (2011-2020).

Wang, Z., Wei, L., Peng, S., Deng, L., and Niu, B. (2018). Child-Trafficking Networks of Illegal Adoption in China. Nature Sustainability, 1(5): 254-260.

Wei, Y., and Zhang, L. (2014). Re-examination of the Yicheng Two-Child Program. The China Journal, (72): 98-120.

Whyte, M. K., Feng, W., and Cai, Y. (2015). Challenging Myths about China's OneChild Policy. The China Journal, (74): 144-159.

Wu, Z., Viisainen, K., Hemminki, E. (2006). Determinants of High Sex Ratio among Newborns: A Cohort Study from Rural Anhui Province, China. Reproductive Health Matters, 14(27), 172-180.

Xing, H. (2015). Studying the Crime of Selling Own Children. Journal of People's Public Security, University of China (Social Sciences Edition), 33(4): 17-24.

-, Chen, R., and Xu, F. (2013). Characteristics of Child Trafficking Development: Analysis on 447 Sentencing Documents. Juvenile Delinquency Prevention Research, 2017(1): 38-43. 
Yao, Y. (2005). The Difficulty of Collecting Social Raising Fund and Its Solutions. Population and Family Planning (in Chinese), 8(1): 21-22.

Zhang, J. (2017). The Evolution of China's One-Child Policy and Its Effects on Family Outcomes. Journal of Economic Perspectives, 31(1): 141-160.

Zhang, W. (2006). Who Adopts Girls and Why? Domestic Adoption of Female Children in Contemporary Rural China. The China Journal, (56): 63-82. 


\section{Appendix}

\subsection{Tables}

Table 1: Fines and Socioeconomic Factors

\begin{tabular}{|c|c|c|c|}
\hline & (1) & (2) & (3) \\
\hline Dep var: Fine & $1988-2001$ & $1995-2001$ & 1981-2001 \\
\hline \multirow[t]{2}{*}{ In real GDP per capita } & -0.198 & -0.174 & 0.253 \\
\hline & $(0.598)$ & $(0.948)$ & $(0.291)$ \\
\hline \multirow[t]{2}{*}{ In cargo transport } & -0.043 & 0.248 & 0.124 \\
\hline & $(0.164)$ & $(0.723)$ & $(0.140)$ \\
\hline \multirow[t]{2}{*}{ ln wage level } & -0.037 & -0.033 & 0.142 \\
\hline & $(0.313)$ & $(0.254)$ & $(0.313)$ \\
\hline \multirow[t]{2}{*}{ Province secretary term } & $0.041 *$ & 0.014 & 0.028 \\
\hline & $(0.023)$ & $(0.026)$ & $(0.019)$ \\
\hline \multirow[t]{2}{*}{ Province secretary age } & 0.0312 & -0.199 & 0.064 \\
\hline & $(0.233)$ & $(0.331)$ & $(0.127)$ \\
\hline \multirow[t]{2}{*}{ Province secretary age sq } & $-3 e^{-4}$ & 0.002 & $-5.49 \mathrm{e}^{-4}$ \\
\hline & $(0.002)$ & $(0.003)$ & $(0.001)$ \\
\hline \multirow[t]{2}{*}{ Province governor term } & $-0.064 * *$ & -0.032 & -0.046 \\
\hline & $(0.025)$ & $(0.036)$ & $(0.029)$ \\
\hline \multirow[t]{2}{*}{ Province governor age } & 0.052 & -0.059 & 0.061 \\
\hline & $(0.040)$ & $(0.080)$ & $(0.040)$ \\
\hline \multirow[t]{2}{*}{ Province governor age sq } & $-3.57 \mathrm{e}^{-4}$ & $6.06 \mathrm{e}^{-4}$ & $-4.61 \mathrm{e}^{-4}$ \\
\hline & $\left(4.33 \mathrm{e}^{-4}\right)$ & $\left(8.59 e^{-4}\right)$ & $\left(4.14 \mathrm{e}^{-4}\right)$ \\
\hline \multirow[t]{2}{*}{ Fiscal revenue/GDP } & & 0.356 & \\
\hline & & $(0.898)$ & \\
\hline \multirow[t]{2}{*}{ Fiscal revenue/expenditure } & & -0.035 & \\
\hline & & $(0.412)$ & \\
\hline Percentage of production teams & & & -0.362 \\
\hline enrolled in HRS & & & $(0.916)$ \\
\hline Observations & 316 & 149 & 409 \\
\hline R-squared & 0.674 & 0.913 & 0.616 \\
\hline provFE & $\mathrm{Y}$ & Y & $\mathrm{Y}$ \\
\hline yearFE & $\mathrm{Y}$ & $\mathrm{Y}$ & $\mathrm{Y}$ \\
\hline Number of clusters & 27 & 25 & 22 \\
\hline
\end{tabular}

Note: All economic variables are in real values using 1980 price levels. Transportation is measured by the logarithm of total cargo transportation in local provinces each year. Column 2 has fewer observations due to missing values of fiscal variables. Column 3 controls for the percentage of production teams enrolled in the Household Responsibility System (HRS) in Chinese provinces, for which data was collected from the Provincial Gazetteers, with records of Anhui, Shaanxi, Inner Mongolia, Tibet and Xinjiang missing between 1981 and 1983. Bootstrapped standard errors clustered at the provincial level are shown in parentheses. ${ }^{* * *} \mathrm{p}<0.01, * * \mathrm{p}<0.05, * \mathrm{p}<0.1$ 
Table 2: Fines and Child Abandonment (1988-2001)

\begin{tabular}{|c|c|c|c|c|c|c|}
\hline & (1) & (2) & (3) & (4) & (5) & $(6)$ \\
\hline Dep var: abandonment & All & Boys & Girls & All & All & All \\
\hline Mean & 2.15 & 0.47 & 1.68 & 2.15 & 2.15 & 2.15 \\
\hline \multirow[t]{2}{*}{ Local fine } & $0.300 * * *$ & 0.044 & $0.250 * * *$ & $0.300 * * *$ & $0.310 * * *$ & $0.310^{* * *}$ \\
\hline & $(0.089)$ & $(0.036)$ & $(0.076)$ & $(0.084)$ & $(0.094)$ & $(0.090)$ \\
\hline Avg. fine in 1st-order & 0.064 & 0.053 & 0.011 & 0.064 & 0.130 & 0.110 \\
\hline neighboring regions & $(0.240)$ & $(0.090)$ & $(0.210)$ & $(0.240)$ & $(0.230)$ & $(0.220)$ \\
\hline \multirow[t]{2}{*}{ ln density } & -0.140 & 0.012 & -0.150 & -0.140 & & \\
\hline & $(0.230)$ & $(0.095)$ & $(0.200)$ & $(0.180)$ & & \\
\hline \multirow[t]{2}{*}{$\ln$ arrest } & 0.190 & 0.039 & 0.150 & 0.190 & & \\
\hline & $(0.160)$ & $(0.077)$ & $(0.130)$ & $(0.150)$ & & \\
\hline \multirow[t]{2}{*}{ Province secretary term } & -0.008 & 0.003 & -0.011 & -0.008 & & \\
\hline & $(0.026)$ & $(0.009)$ & $(0.024)$ & $(0.024)$ & & \\
\hline \multirow[t]{2}{*}{ Province secretary age } & 0.006 & 0.035 & -0.029 & 0.006 & & \\
\hline & $(0.061)$ & $(0.024)$ & $(0.057)$ & $(0.070)$ & & \\
\hline \multirow[t]{2}{*}{ Province secretary age sq } & $2 \mathrm{e}^{-5}$ & $-3 e^{-4}$ & $4 \mathrm{e}^{-4}$ & $2 e^{-5}$ & & \\
\hline & $\left(6 \mathrm{e}^{-4}\right)$ & $\left(2 \mathrm{e}^{-4}\right)$ & $\left(6 \mathrm{e}^{-4}\right)$ & $\left(7 e^{-4}\right)$ & & \\
\hline \multirow[t]{2}{*}{ Province governor term } & $-0.044 *$ & 0.007 & $-0.051 * *$ & $-0.044^{*}$ & & \\
\hline & $(0.023)$ & $(0.008)$ & $(0.020)$ & $(0.024)$ & & \\
\hline \multirow[t]{2}{*}{ Province governor age } & 0.029 & 0.033 & -0.004 & 0.029 & & \\
\hline & $(0.040)$ & $(0.021)$ & $(0.037)$ & $(0.056)$ & & \\
\hline \multirow[t]{2}{*}{ Province governor age sq } & $-4 e^{-4}$ & $-3 e^{-4}$ & $-1 \mathrm{e}^{-4}$ & $-4 e^{-4}$ & & \\
\hline & $\left(4 \mathrm{e}^{-4}\right)$ & $\left(2 e^{-4}\right)$ & $\left(4 \mathrm{e}^{-4}\right)$ & $\left(6 e^{-4}\right)$ & & \\
\hline Observations & 3,461 & 3,461 & 3,461 & 3,461 & 3,461 & 3,461 \\
\hline R-squared & 0.722 & 0.497 & 0.687 & 0.722 & 0.721 & 0.626 \\
\hline prefFE & $\mathrm{Y}$ & $\mathrm{Y}$ & $\mathrm{Y}$ & $\mathrm{Y}$ & Y & $\mathrm{Y}$ \\
\hline yearFE & $\mathrm{Y}$ & $\mathrm{Y}$ & $\mathrm{Y}$ & $\mathrm{Y}$ & Y & $\mathrm{Y}$ \\
\hline Trend & pref & pref & pref & pref & pref & prov \\
\hline Cluster by & pref & pref & pref & prov-year & pref & pref \\
\hline Number of clusters & 276 & 276 & 276 & 396 & 276 & 276 \\
\hline
\end{tabular}

Note: The dependent variable is the number of child abandonment. The fine levels in neighboring provinces are the populationweighted average fines in corresponding neighboring provinces. Standard errors clustered at the prefecture level are shown in parentheses for all columns except column 4. Standard errors in column 4 are clustered at the provincial-year level. *** $\mathrm{p}<0.01$, $* * \mathrm{p}<0.05,{ }^{*} \mathrm{p}<0.1$ 
Table 3: Fines and Child Abduction (1988-2001)

\begin{tabular}{|c|c|c|c|c|c|c|}
\hline & (1) & (2) & (3) & (4) & (5) & (6) \\
\hline Dep var: abduction & All & Boys & Girls & All & All & All \\
\hline Mean & 2.80 & 2.05 & 0.75 & 2.80 & 2.80 & 2.80 \\
\hline \multirow[t]{2}{*}{ Local fine } & $2 \mathrm{e}^{-4}$ & -0.033 & 0.033 & $2 e^{-4}$ & -0.043 & -0.090 \\
\hline & $(0.220)$ & $(0.220)$ & $(0.048)$ & $(0.250)$ & $(0.250)$ & $(0.250)$ \\
\hline \multirow{2}{*}{$\begin{array}{l}\text { Avg. fine in 1st-order } \\
\text { neighboring regions }\end{array}$} & $1.000 * * *$ & $0.890^{* *}$ & 0.110 & $1.000^{* *}$ & $0.850^{* *}$ & $0.840^{*}$ \\
\hline & $(0.370)$ & $(0.350)$ & $(0.095)$ & $(0.440)$ & $(0.430)$ & $(0.430)$ \\
\hline \multirow[t]{2}{*}{ ln density } & 1.010 & 0.920 & 0.095 & $1.010^{* *}$ & & \\
\hline & $(0.710)$ & $(0.720)$ & $(0.089)$ & $(0.430)$ & & \\
\hline \multirow[t]{2}{*}{$\ln$ arrest } & -0.840 & -0.770 & -0.071 & -0.840 & & \\
\hline & $(0.700)$ & $(0.630)$ & $(0.100)$ & $(0.600)$ & & \\
\hline \multirow[t]{2}{*}{ Province secretary term } & -0.048 & -0.046 & -0.002 & -0.048 & & \\
\hline & $(0.033)$ & $(0.031)$ & $(0.010)$ & $(0.035)$ & & \\
\hline \multirow[t]{2}{*}{ Province secretary age } & 0.049 & 0.043 & 0.006 & 0.049 & & \\
\hline & $(0.120)$ & $(0.110)$ & $(0.035)$ & $(0.110)$ & & \\
\hline \multirow[t]{2}{*}{ Province secretary age sq } & $-3 e^{-4}$ & $-3 e^{-4}$ & $-5 e^{-5}$ & $-3 e^{-4}$ & & \\
\hline & $(0.001)$ & $(0.001)$ & $\left(4 \mathrm{e}^{-4}\right)$ & $(0.001)$ & & \\
\hline \multirow[t]{2}{*}{ Province governor term } & 0.020 & 0.024 & -0.005 & 0.020 & & \\
\hline & $(0.028)$ & $(0.028)$ & $(0.012)$ & $(0.049)$ & & \\
\hline \multirow[t]{2}{*}{ Province governor age } & 0.015 & 0.031 & -0.016 & 0.015 & & \\
\hline & $(0.059)$ & $(0.053)$ & $(0.024)$ & $(0.069)$ & & \\
\hline \multirow[t]{2}{*}{ Province governor age sq } & $-2 e^{-4}$ & $-3 e^{-4}$ & $2 \mathrm{e}^{-4}$ & $-2 e^{-4}$ & & \\
\hline & $\left(6 \mathrm{e}^{-4}\right)$ & $\left(6 \mathrm{e}^{-4}\right)$ & $\left(3 \mathrm{e}^{-4}\right)$ & $(0.001)$ & & \\
\hline Observations & 3,461 & 3,461 & 3,461 & 3,461 & 3,461 & 3,461 \\
\hline R-squared & 0.856 & 0.825 & 0.625 & 0.856 & 0.855 & 0.825 \\
\hline prefFE & $\mathrm{Y}$ & $\mathrm{Y}$ & $\mathrm{Y}$ & $\mathrm{Y}$ & $\mathrm{Y}$ & $\mathrm{Y}$ \\
\hline yearFE & $\mathrm{Y}$ & $\mathrm{Y}$ & $\mathrm{Y}$ & $\mathrm{Y}$ & $\mathrm{Y}$ & $\mathrm{Y}$ \\
\hline trend & pref & pref & pref & pref & pref & prov \\
\hline Cluster by & pref & pref & pref & prov-year & pref & pref \\
\hline Number of clusters & 276 & 276 & 276 & 396 & 276 & 276 \\
\hline
\end{tabular}

Note: The dependent variable is the number of child abduction. The fine levels in neighboring provinces are the populationweighted average fines in corresponding neighboring provinces. Standard errors clustered at the prefecture level are shown in parentheses for all columns except column 4 . Standard errors in column 4 are clustered at the provincial-year level. *** $p<0.01$, $* * \mathrm{p}<0.05, * \mathrm{p}<0.1$ 
Table 4: The Heterogeneity of Fines and Missing Children by Son Preference (1988-2001)

\begin{tabular}{|c|c|c|c|c|c|c|c|c|}
\hline & (1) & (2) & (3) & (4) & (5) & $(6)$ & (7) & (8) \\
\hline & \multicolumn{4}{|c|}{ Abandonment } & \multicolumn{4}{|c|}{ Abduction } \\
\hline & All & Girls & All & Girls & All & Boys & All & Boys \\
\hline \multirow[t]{2}{*}{ Local fine } & 0.100 & 0.099 & 0.120 & 0.110 & 0.009 & -0.023 & -0.094 & -0.140 \\
\hline & $(0.083)$ & $(0.077)$ & $(0.082)$ & $(0.075)$ & $(0.220)$ & $(0.220)$ & $(0.190)$ & $(0.29)$ \\
\hline \multirow[t]{2}{*}{ Fine in 1 st-order nbr } & 0.071 & 0.016 & -0.410 & -0.280 & 0.610 & 0.420 & 0.630 & 0.430 \\
\hline & $(0.240)$ & $(0.210)$ & $(0.400)$ & $(0.350)$ & $(0.380)$ & $(0.340)$ & $(0.390)$ & $(0.28)$ \\
\hline \multirow[t]{2}{*}{ Fine*D(high SRB) } & $0.450^{* *}$ & $0.360 * *$ & $0.440^{* *}$ & $0.350^{* *}$ & & & 0.240 & 0.280 \\
\hline & $(0.200)$ & $(0.170)$ & $(0.190)$ & $(0.170)$ & & & $(0.320)$ & $(0.29)$ \\
\hline Fine in 1 st-order nbr* & & & $0.820^{*}$ & 0.510 & 0.660 & $0.800 * *$ & 0.650 & $0.790^{* *}$ \\
\hline $\mathrm{D}($ nbr high SRB $)$ & & & $(0.440)$ & $(0.370)$ & $(0.430)$ & $(0.370)$ & $(0.430)$ & $(0.33)$ \\
\hline Observations & 3,461 & 3,461 & 3,461 & 3,461 & 3,461 & 3,461 & 3,461 & 3,461 \\
\hline R-squared & 0.724 & 0.688 & 0.725 & 0.689 & 0.856 & 0.825 & 0.856 & 0.825 \\
\hline prefFE & $\mathrm{Y}$ & $\mathrm{Y}$ & $\mathrm{Y}$ & $\mathrm{Y}$ & $\mathrm{Y}$ & $\mathrm{Y}$ & $\mathrm{Y}$ & $\mathrm{Y}$ \\
\hline yearFE & $\mathrm{Y}$ & $\mathrm{Y}$ & $\mathrm{Y}$ & $\mathrm{Y}$ & $\mathrm{Y}$ & $\mathrm{Y}$ & $\mathrm{Y}$ & Y \\
\hline preftrend & $\mathrm{Y}$ & $\mathrm{Y}$ & $\mathrm{Y}$ & $\mathrm{Y}$ & $\mathrm{Y}$ & $\mathrm{Y}$ & $\mathrm{Y}$ & $\mathrm{Y}$ \\
\hline Number of clusters & 276 & 276 & 276 & 276 & 276 & 276 & 276 & 276 \\
\hline
\end{tabular}

Note: The dependent variables are the number of child abandonment and abduction separately. All regressions control logarithm of population density, logarithm of total criminal arrests and provincial secretary and governor characteristics (age, age square and terms). A prefecture is classified as having a strong preference for boys if the sex ratio at birth (SRB) in 2010 was no less than 1.17. Standard errors clustered at the prefecture level are shown in parentheses. ${ }^{* * *} \mathrm{p}<0.01,{ }^{* *} \mathrm{p}<0.05,{ }^{*}$ $\mathrm{p}<0.1$ 
Table 5: Fines and Missing Children after 2001 (2002-2016)

\begin{tabular}{|c|c|c|c|c|c|c|}
\hline & (1) & $(2)$ & (3) & (4) & (5) & $(6)$ \\
\hline & \multicolumn{3}{|c|}{ Abandonment } & \multicolumn{3}{|c|}{ Abduction } \\
\hline & All & Boys & Girls & All & Boys & Girls \\
\hline \multirow[t]{2}{*}{ Local fine } & -0.014 & $-0.016 * *$ & 0.003 & -0.028 & -0.052 & 0.025 \\
\hline & $(0.015)$ & $(0.008)$ & $(0.013)$ & $(0.041)$ & $(0.038)$ & $(0.027)$ \\
\hline \multirow{2}{*}{$\begin{array}{l}\text { Fine in 1st-order } \\
\text { neighbor }\end{array}$} & -0.040 & -0.043 & 0.004 & -0.048 & -0.032 & -0.016 \\
\hline & $(0.050)$ & $(0.028)$ & $(0.047)$ & $(0.140)$ & $(0.120)$ & $(0.092)$ \\
\hline \multirow[t]{2}{*}{ ln density } & 0.350 & 0.180 & 0.170 & $-2.230 * *$ & -1.940 & -0.280 \\
\hline & $(0.240)$ & $(0.130)$ & $(0.170)$ & $(0.990)$ & $(1.220)$ & $(0.480)$ \\
\hline \multirow[t]{2}{*}{$\ln$ arrest } & 0.072 & 0.022 & 0.049 & 0.210 & 0.070 & 0.140 \\
\hline & $(0.048)$ & $(0.024)$ & $(0.039)$ & $(0.140)$ & $(0.094)$ & $(0.097)$ \\
\hline \multirow[t]{2}{*}{ Province secretary term } & 0.270 & 0.150 & 0.120 & $-2.550 * *$ & $-2.350 *$ & -0.210 \\
\hline & $(0.290)$ & $(0.120)$ & $(0.230)$ & $(1.100)$ & $(1.270)$ & $(0.480)$ \\
\hline \multirow[t]{2}{*}{ Province secretary age } & 0.061 & 0.013 & 0.048 & 0.160 & 0.041 & 0.120 \\
\hline & $(0.048)$ & $(0.023)$ & $(0.041)$ & $(0.140)$ & $(0.091)$ & $(0.100)$ \\
\hline \multirow[t]{2}{*}{ Province secretary age sq } & $3 \mathrm{e}^{-4}$ & -0.002 & 0.002 & 0.013 & 0.006 & 0.007 \\
\hline & $(0.005)$ & $(0.003)$ & $(0.004)$ & $(0.018)$ & $(0.014)$ & $(0.010)$ \\
\hline \multirow[t]{2}{*}{ Province governor term } & 0.027 & -0.019 & 0.046 & -0.130 & -0.003 & -0.130 \\
\hline & $(0.048)$ & $(0.025)$ & $(0.048)$ & $(0.140)$ & $(0.120)$ & $(0.120)$ \\
\hline \multirow[t]{2}{*}{ Province governor age } & $-3 e^{-4}$ & $2 e^{-4}$ & $-4 e^{-4}$ & 0.001 & $-1 e^{-4}$ & 0.001 \\
\hline & $\left(4 \mathrm{e}^{-4}\right)$ & $\left(2 \mathrm{e}^{-4}\right)$ & $\left(4 \mathrm{e}^{-4}\right)$ & $(0.001)$ & $(0.001)$ & $(0.001)$ \\
\hline \multirow[t]{2}{*}{ Province governor age sq } & $-4 e^{-4}$ & -0.002 & 0.002 & -0.003 & -0.015 & 0.012 \\
\hline & $(0.007)$ & $(0.004)$ & $(0.006)$ & $(0.019)$ & $(0.013)$ & $(0.012)$ \\
\hline Observations & 3,609 & 3,609 & 3,609 & 3,609 & 3,609 & 3,609 \\
\hline R-squared & 0.400 & 0.272 & 0.352 & 0.767 & 0.721 & 0.533 \\
\hline prefFE & $\mathrm{Y}$ & $\mathrm{Y}$ & $\mathrm{Y}$ & Y & Y & Y \\
\hline yearFE & $\mathrm{Y}$ & $\mathrm{Y}$ & $\mathrm{Y}$ & $\mathrm{Y}$ & $\mathrm{Y}$ & $\mathrm{Y}$ \\
\hline preftrend & $\mathrm{Y}$ & $\mathrm{Y}$ & $\mathrm{Y}$ & Y & $\mathrm{Y}$ & Y \\
\hline Number of clusters & 287 & 287 & 287 & 287 & 287 & 287 \\
\hline
\end{tabular}

Note: The dependent variables are the number of child abandonment and abduction separately. Standard errors clustered at the prefecture level are shown in parentheses. ${ }^{* * *} \mathrm{p}<0.01,{ }^{* *} \mathrm{p}<0.05,{ }^{*} \mathrm{p}<0.1$ 
Table 6: Robustness Checks

\begin{tabular}{|c|c|c|c|c|c|c|c|c|}
\hline & $\begin{array}{l}(1) \\
\ln \end{array}$ & $\begin{array}{l}(2) \\
\text { Tobit }\end{array}$ & $\begin{array}{l}(3) \\
\text { Remove } \\
\text { capital }\end{array}$ & $\begin{array}{l}(4) \\
\text { Remove } \\
\text { minority }\end{array}$ & $\begin{array}{l}(5) \\
\text { Nonlinear } \\
\text { trend }\end{array}$ & $\begin{array}{l}(6) \\
\text { Other } \\
\text { controls }\end{array}$ & $\begin{array}{l}(7) \\
\text { Expanded } \\
\text { abandonment }\end{array}$ & $\begin{array}{l}(8) \\
1990- \\
2001\end{array}$ \\
\hline \multicolumn{9}{|l|}{ A: Abandonment } \\
\hline \multirow[t]{2}{*}{ Local fine } & $0.034^{*}$ & $0.250 * * *$ & $0.280 * * *$ & $0.370 * * *$ & $0.200^{*}$ & $0.260 * *$ & $0.330 * * *$ & $0.220 * *$ \\
\hline & $(0.020)$ & $(0.074)$ & $(0.088)$ & $(0.110)$ & $(0.120)$ & $(0.120)$ & $(0.110)$ & $(0.092)$ \\
\hline \multirow[t]{2}{*}{ Fine in $1^{\text {st }}$-order neighbor } & -0.071 & -0.009 & -0.140 & 0.120 & -0.0110 & 0.260 & 0.180 & -0.200 \\
\hline & $(0.050)$ & $(0.160)$ & $(0.210)$ & $(0.250)$ & $(0.250)$ & $(0.330)$ & $(0.240)$ & $(0.240)$ \\
\hline Observations & 3,461 & 3,462 & 3,065 & 3,163 & 3,461 & 2,477 & 2,961 & 3,461 \\
\hline R-squared & 0.682 & & 0.673 & 0.723 & 0.760 & 0.746 & 0.748 & 0.769 \\
\hline \multicolumn{9}{|l|}{ B: Abduction } \\
\hline \multirow[t]{2}{*}{ Local fine } & 0.029 & -0.073 & -0.038 & 0.004 & 0.310 & -0.260 & & 0.100 \\
\hline & $(0.021)$ & $(0.110)$ & $(0.220)$ & $(0.260)$ & $(0.250)$ & $(0.200)$ & & $(0.190)$ \\
\hline \multirow[t]{2}{*}{ Fine in $1^{\text {st }}$-order neighbor } & $0.150 * * *$ & 0.280 & $0.740 * *$ & $1.160 * * *$ & $1.210 * * *$ & $1.370 * * *$ & & $1.430 * * *$ \\
\hline & $(0.055)$ & $(0.230)$ & $(0.300)$ & $(0.380)$ & $(0.340)$ & $(0.310)$ & & $(0.460)$ \\
\hline Observations & 3,461 & 3,462 & 3,065 & 3,163 & 3,461 & 2,477 & & 2,961 \\
\hline R-squared & 0.754 & & 0.788 & 0.858 & 0.898 & 0.872 & & 0.851 \\
\hline prefFE & $\mathrm{Y}$ & $\mathrm{Y}$ & $\mathrm{Y}$ & $\mathrm{Y}$ & $\mathrm{Y}$ & $\mathrm{Y}$ & $\mathrm{Y}$ & $\mathrm{Y}$ \\
\hline yearFE & $\mathrm{Y}$ & $\mathrm{Y}$ & $\mathrm{Y}$ & $\mathrm{Y}$ & $\mathrm{Y}$ & $\mathrm{Y}$ & $\mathrm{Y}$ & $\mathrm{Y}$ \\
\hline preftrend & $\mathrm{Y}$ & & $\mathrm{Y}$ & $\mathrm{Y}$ & $\mathrm{Y}$ & $\mathrm{Y}$ & $\mathrm{Y}$ & $\mathrm{Y}$ \\
\hline Number of clusters & 276 & & 246 & 250 & 276 & 271 & 276 & 276 \\
\hline
\end{tabular}

Note: Column 5 includes both linear and quadratic year trends for each prefecture. Column 6 includes controls for children under five years of age and a logarithm of GDP per capita in local prefectures. The dependent variable in column 7 is the total of abandoned children plus abducted girls. Standard errors are in parentheses. All regressions control logarithm of population density, logarithm of total criminal arrests and personal characteristics of provincial secretary and governor including their ages, age squares and onoffice terms. Standard errors clustered at the prefecture level are shown in parentheses. except column $2 . * * * p<0.01, * * p<0.05, * p<0.1$ 
Table 7: Fine and Missing Children in Rural and Non-rural Regions (1988-2001)

\begin{tabular}{lllll}
\hline \multirow{2}{*}{ Mean } & \multicolumn{1}{c}{$(1)$} & \multicolumn{1}{c}{$(2)$} & \multicolumn{2}{c}{$(4)$} \\
\cline { 2 - 5 } & \multicolumn{2}{c}{ Abandonment } & \multicolumn{2}{c}{ Abduction } \\
\cline { 2 - 5 } Local fine & Rural & Non-rural & Rural & Non-rural \\
& 0.56 & 1.59 & 0.84 & 1.95 \\
\hline Fine in 1st-order neighbor & $0.140^{* * *}$ & $0.160^{* *}$ & 0.070 & -0.070 \\
& $(0.035)$ & $(0.073)$ & $(0.054)$ & $(0.200)$ \\
Observations & 0.018 & 0.045 & $0.400^{* *}$ & $0.600^{* *}$ \\
R-squared & $(0.087)$ & $(0.200)$ & $(0.160)$ & $(0.250)$ \\
prefFE & 3,461 & 3,461 & 3,461 & 3,461 \\
yearFE & 0.510 & 0.687 & 0.684 & 0.838 \\
preftrend & $\mathrm{Y}$ & $\mathrm{Y}$ & $\mathrm{Y}$ & $\mathrm{Y}$ \\
Number of clusters & $\mathrm{Y}$ & $\mathrm{Y}$ & $\mathrm{Y}$ & $\mathrm{Y}$ \\
\hline
\end{tabular}

Note: The dependent variables are children abandonment and children abduction in rural and non-rural regions in China. An abandonment or abduction cases is identified as rural if the reported lost location is identified to a location in a rural village, and non rural otherwise. All regressions control logarithm of population density, logarithm of total criminal arrests and personal characteristics of provincial secretary and governor including their ages, age squares and on-office terms. Standard errors clustered at the prefecture level are shown in parentheses. ${ }^{* * *} \mathrm{p}<0.01,{ }^{* *} \mathrm{p}<0.05,{ }^{*} \mathrm{p}<0.1$ 
Table 8: The Great Famine and Missing Children (1950-1970)

\begin{tabular}{|c|c|c|c|c|c|c|c|c|c|c|}
\hline & (1) & $(2)$ & (3) & (4) & (5) & (6) & (7) & (8) & (9) & (10) \\
\hline & $\begin{array}{l}\text { All } \\
\text { missing }\end{array}$ & Boys & Girls & Abandoned & Abducted & $\begin{array}{l}\text { All } \\
\text { missing }\end{array}$ & Boys & Girls & Abandoned & Abducted \\
\hline Mean & 3.28 & 1.74 & 1.54 & 2.15 & 1.12 & 3.28 & 1.74 & 1.54 & 2.15 & 1.12 \\
\hline \multirow[t]{2}{*}{ Death rate } & $0.700 *$ & $0.400^{*}$ & $0.290^{*}$ & 0.290 & $0.410^{*}$ & & & & & \\
\hline & $(0.380)$ & $(0.220)$ & $(0.160)$ & $(0.170)$ & $(0.200)$ & & & & & \\
\hline $\mathrm{D}$ (famine & & & & & & $7.750 * * *$ & $4.060 * *$ & $3.690 * * *$ & $3.640 * *$ & $4.110 * * *$ \\
\hline 1959-1961) & & & & & & $(2.790)$ & $(1.550)$ & $(1.280)$ & $(1.390)$ & $(1.450)$ \\
\hline Observations & 546 & 546 & 546 & 546 & 546 & 546 & 546 & 546 & 546 & 546 \\
\hline R-squared & 0.394 & 0.388 & 0.352 & 0.388 & 0.386 & 0.334 & 0.306 & 0.33 & 0.375 & 0.276 \\
\hline provFE & $\mathrm{Y}$ & $\mathrm{Y}$ & $\mathrm{Y}$ & $\mathrm{Y}$ & $\mathrm{Y}$ & $\mathrm{Y}$ & $\mathrm{Y}$ & $\mathrm{Y}$ & Y & $\mathrm{Y}$ \\
\hline
\end{tabular}

Note: The death rate data for the provinces are from Meng, Qian and Yared (2015). The famine dummy variable takes a value of 1 for the years from 1959 to 1961. Standard errors clustered at the provincial level are shown in parentheses. The number of clusters is 29 . *** $\mathrm{p}<0.01, * * \mathrm{p}<0.05, * \mathrm{p}<0.1$ 


\subsection{Figures}

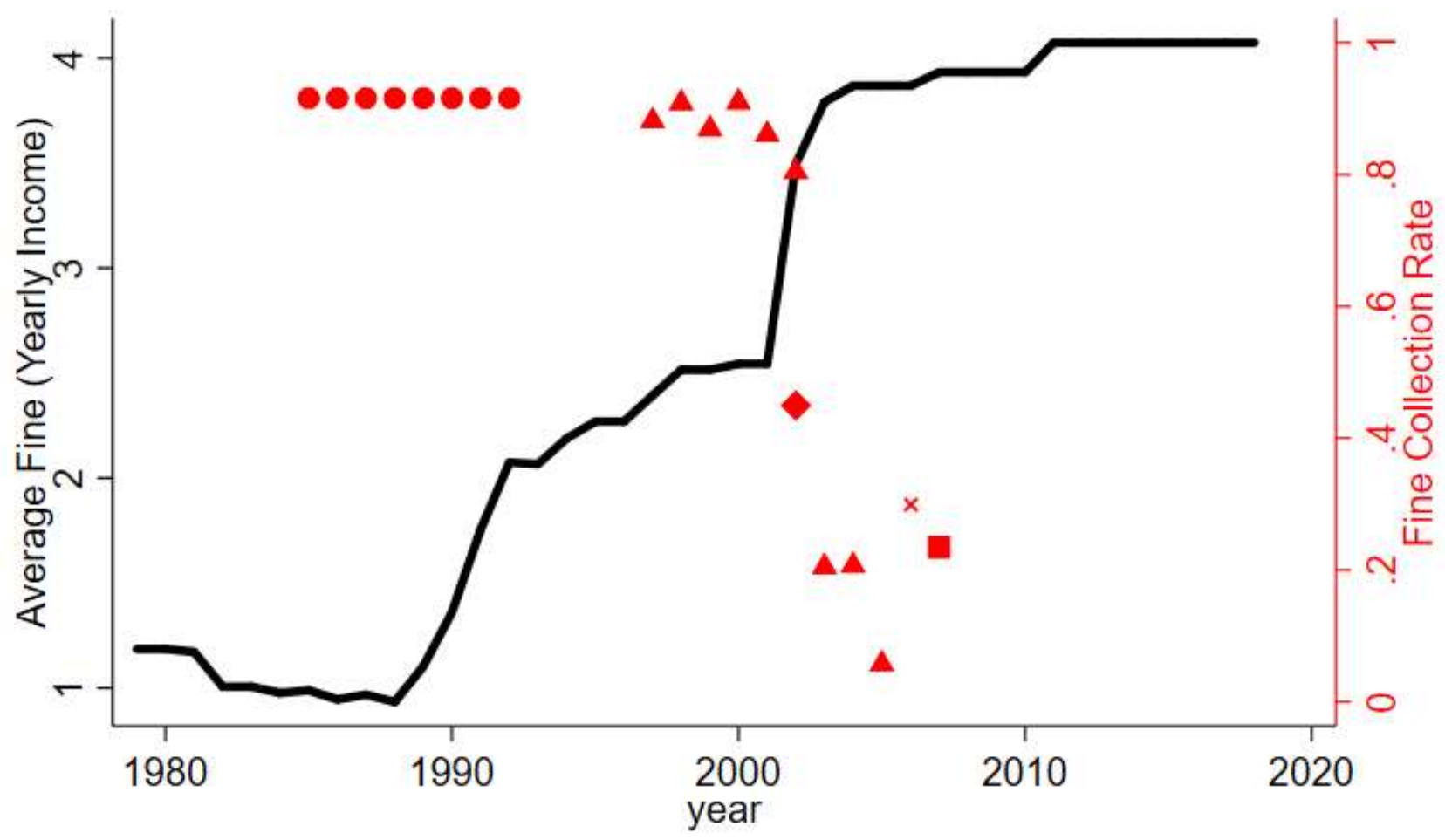

\begin{tabular}{lll}
\hline & Average Fine (Left Axis) & $\bullet$ Hubei (Jiang and Zhang, 1993) \\
$\times \quad$ Hubei (Shi, 2006) & Zhejiang (Huang, 2008) & $\bullet$ Hunan (Cao, 2012)
\end{tabular}

Figure 1: Trend in Fines for the First Unauthorized Birth and Fine Collection Rates

Note: The solid line plots the average per parent fine in the unit of yearly income for the first unauthorized birth for all provinces, while the dots of different shapes give fine collection rates in local regions for different years, based on findings in Jiang and Zhang (1993), Shi (2006), Meng et al. (2008), Huang (2008) and Li (2003). 


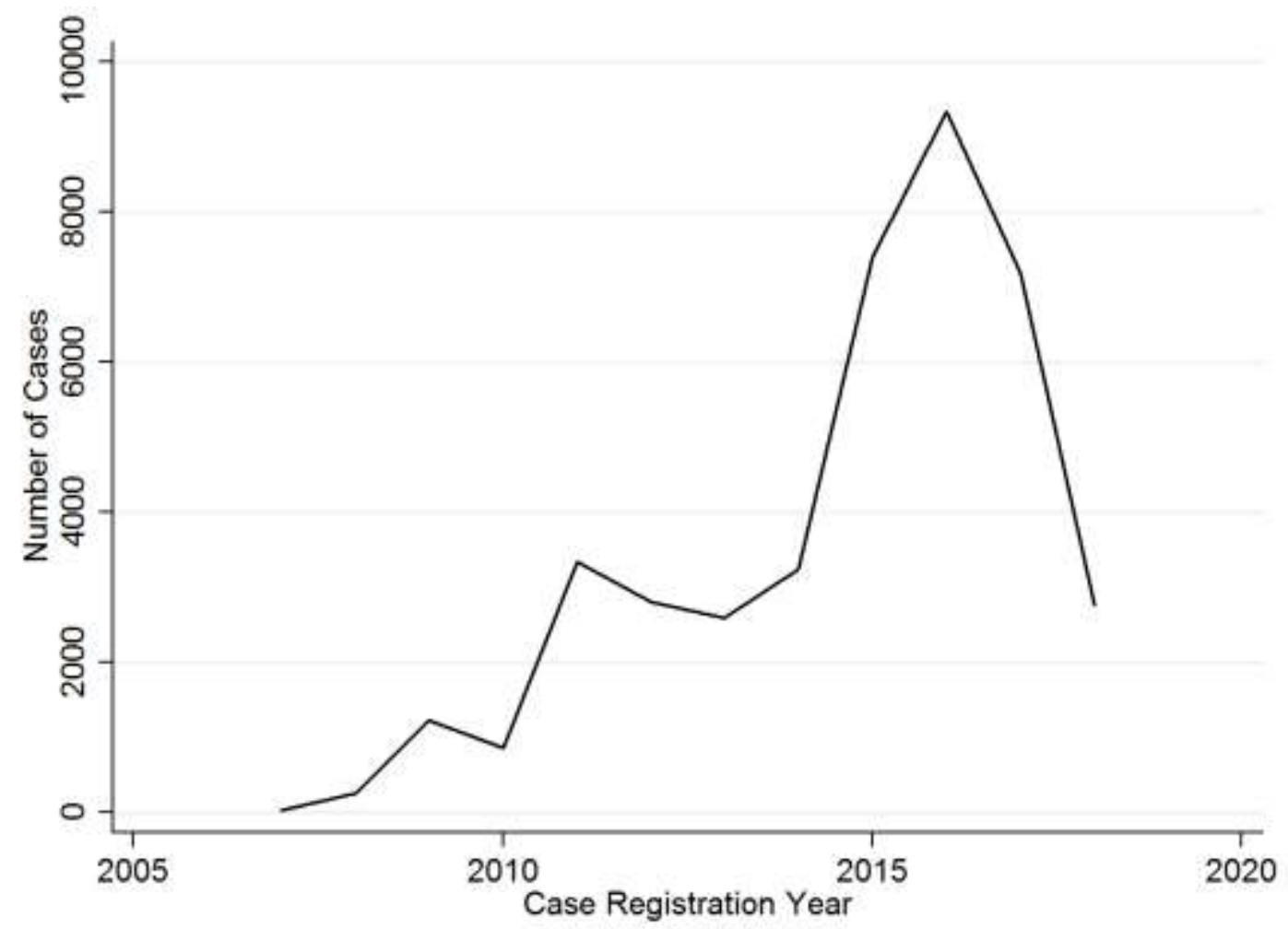

Figure 2: Number of Cases Registered on the Baby Come Back Home Website, by Year 

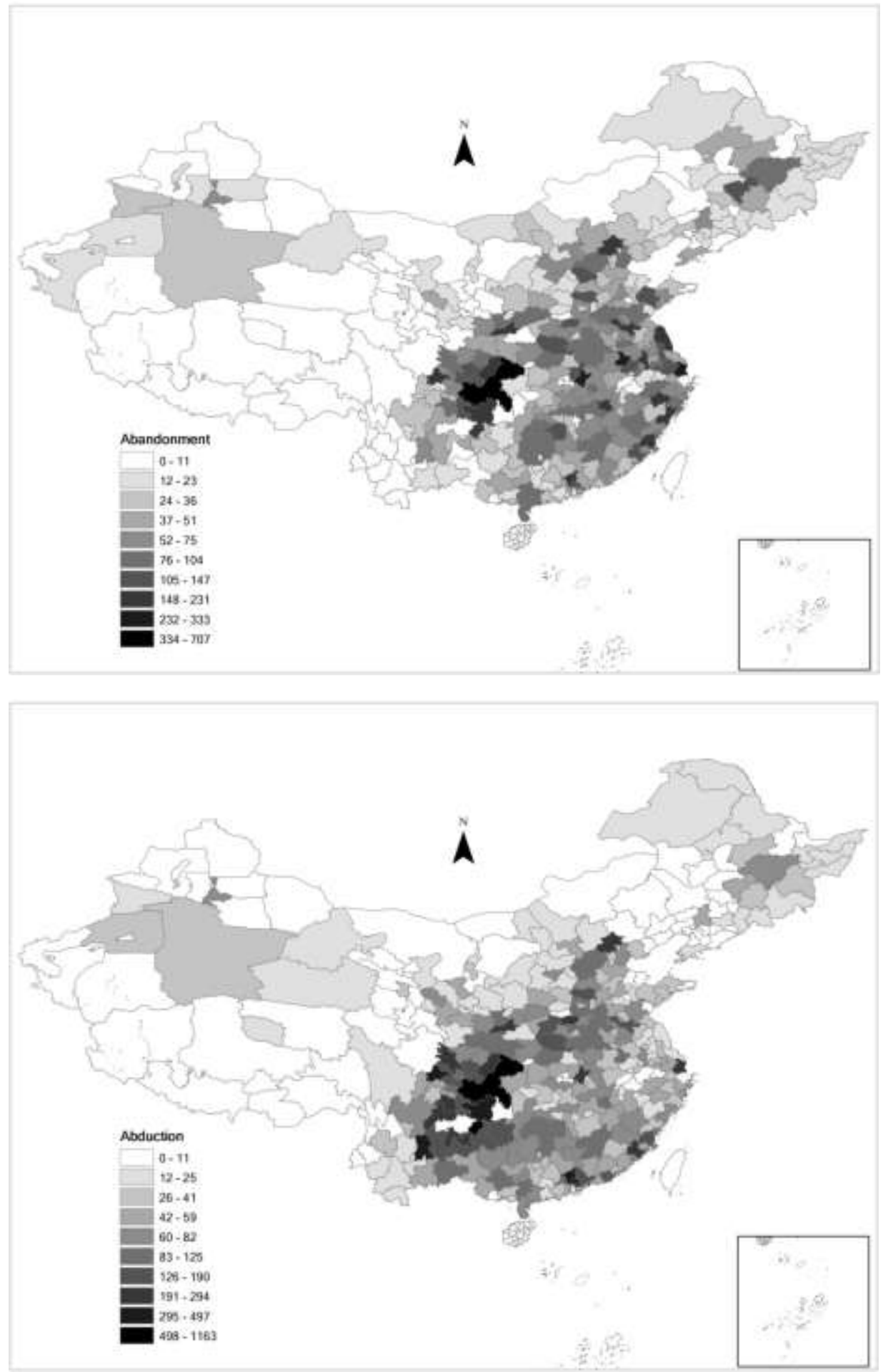

Figure 3: Map of Family-reported Child Abandonment and Abduction in China 


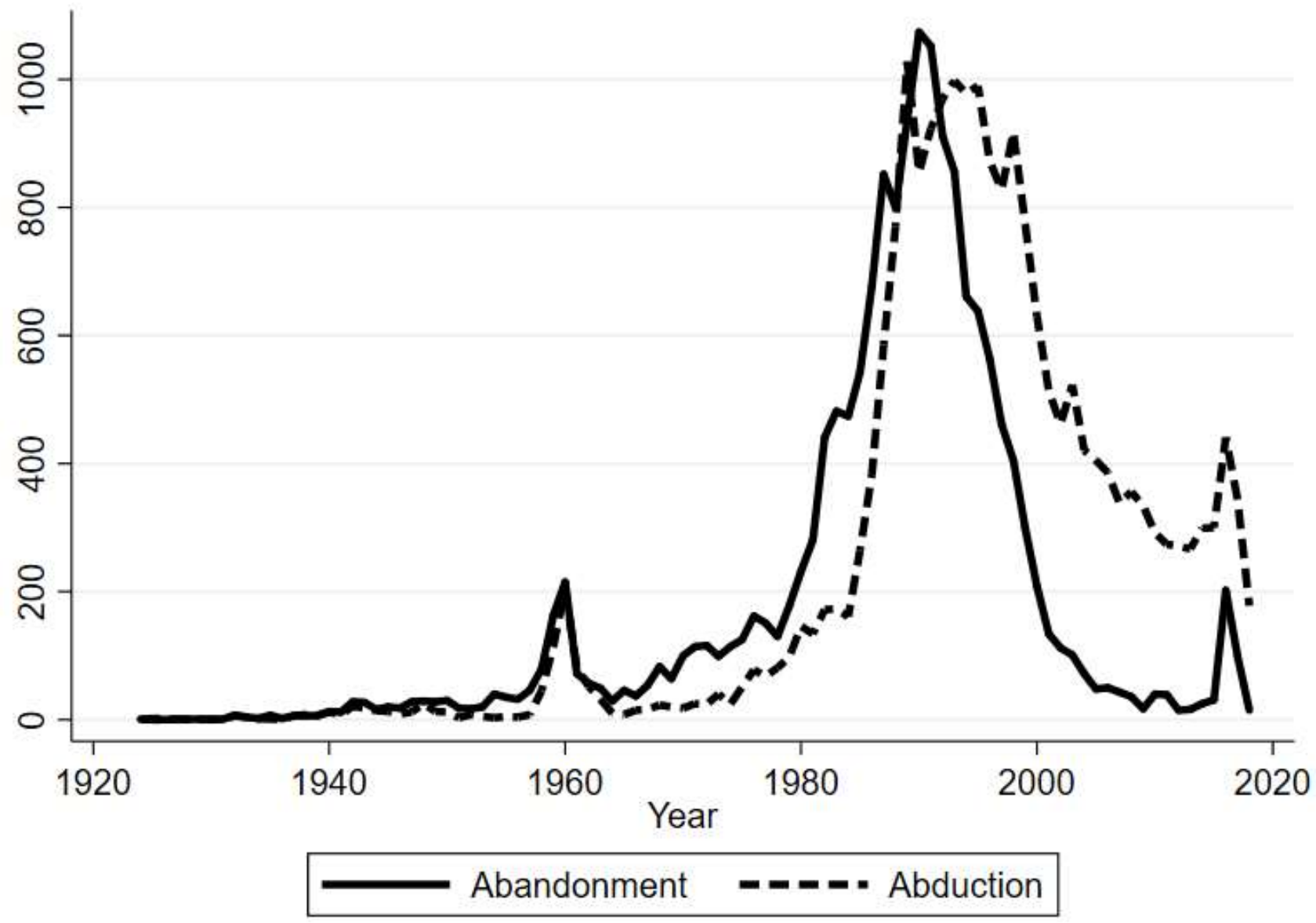

Figure 4: Trend of Family-reported Missing Children in China

Note: All data are from family-reports of families looking for missing children on the website of Baby Come Back Home by June 2018. 


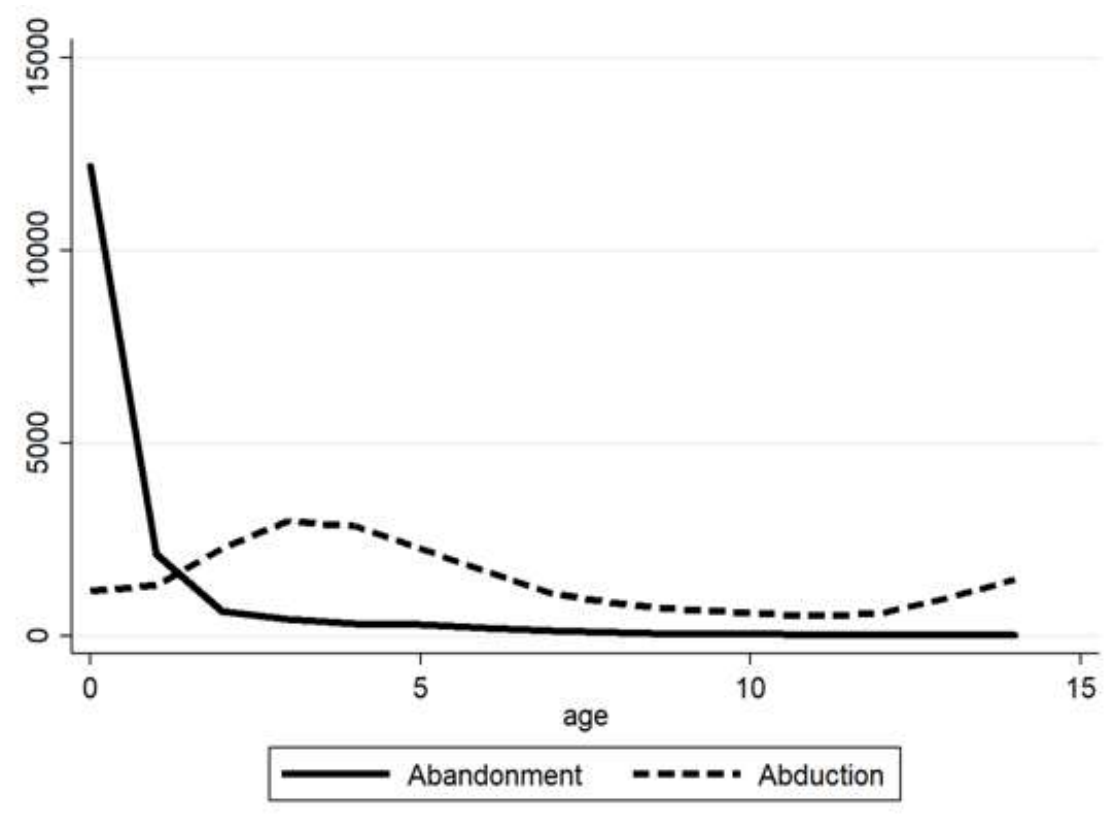

Figure 5: Family-reported Child Abandonment and Child Abduction, by Age

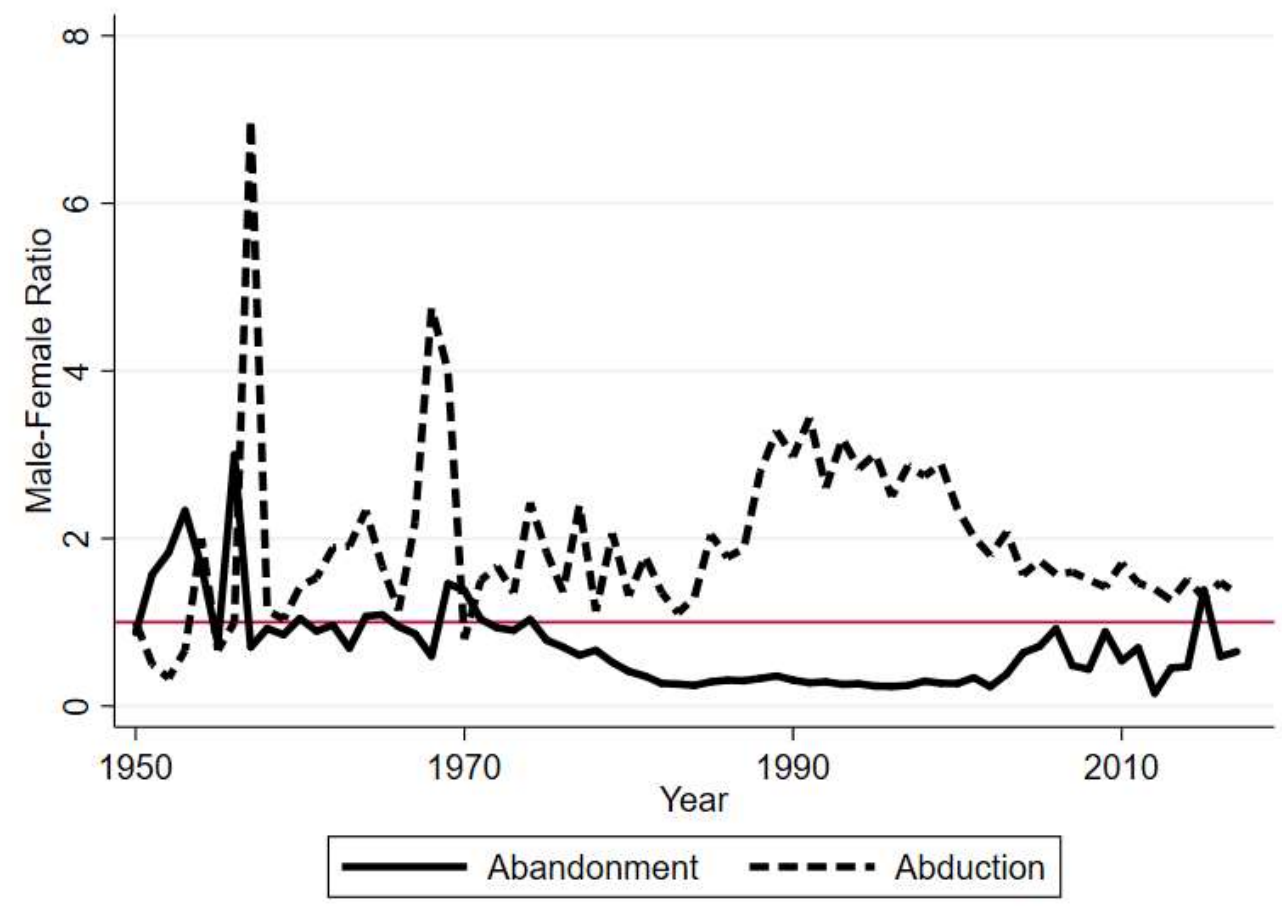

Figure 6: Gender Ratio of Family-reported Missing Children, by Year 


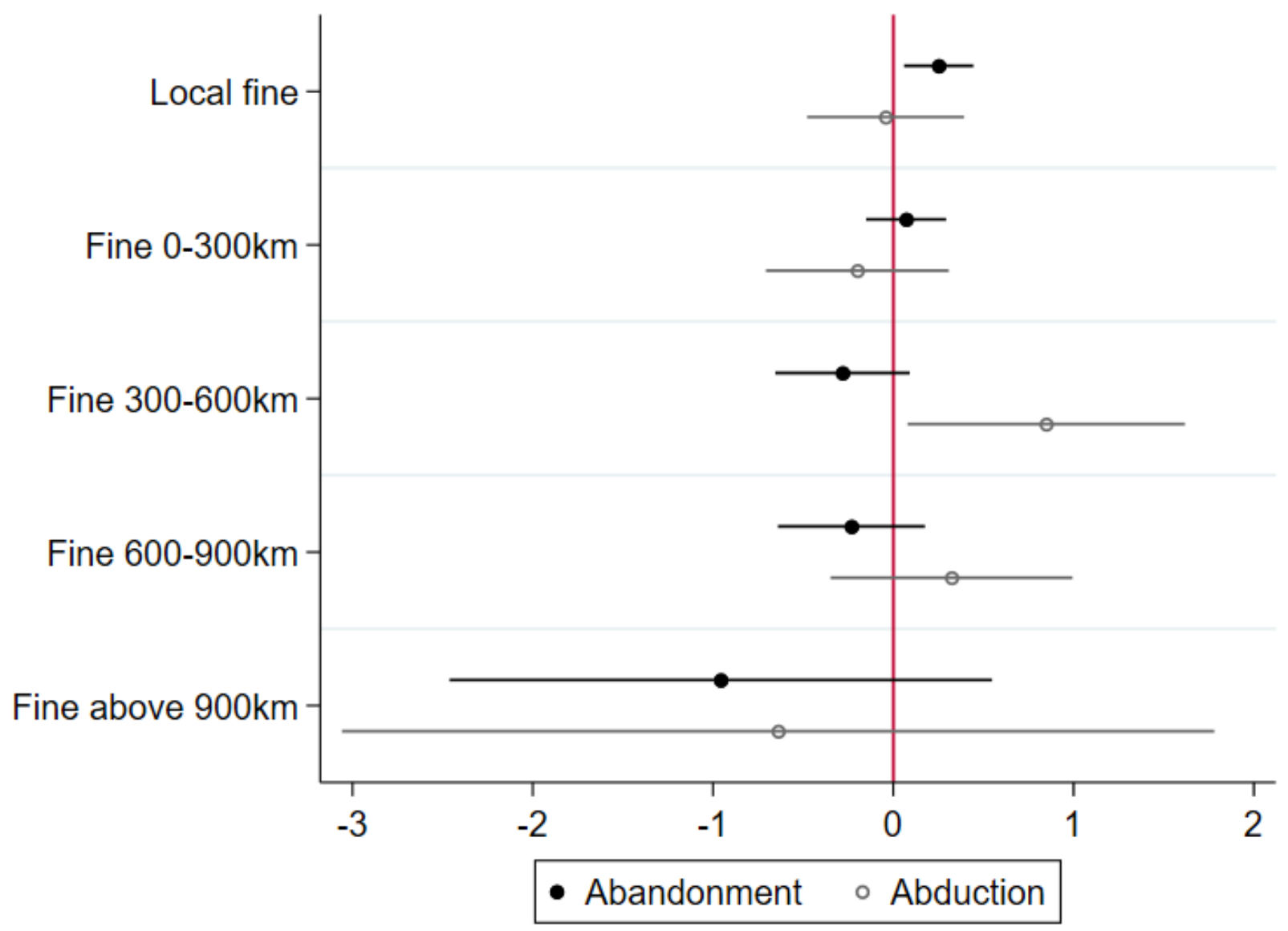

Figure 7: Coefficients of Fines on Child Abandonment and Abduction by Distance

Note: This figure plots out the estimated coefficients and their $95 \%$ confidence intervals of fines in regions with different distance bins away on child abandonment and abduction separately. The specific estimated coefficients are in Table OA2. 

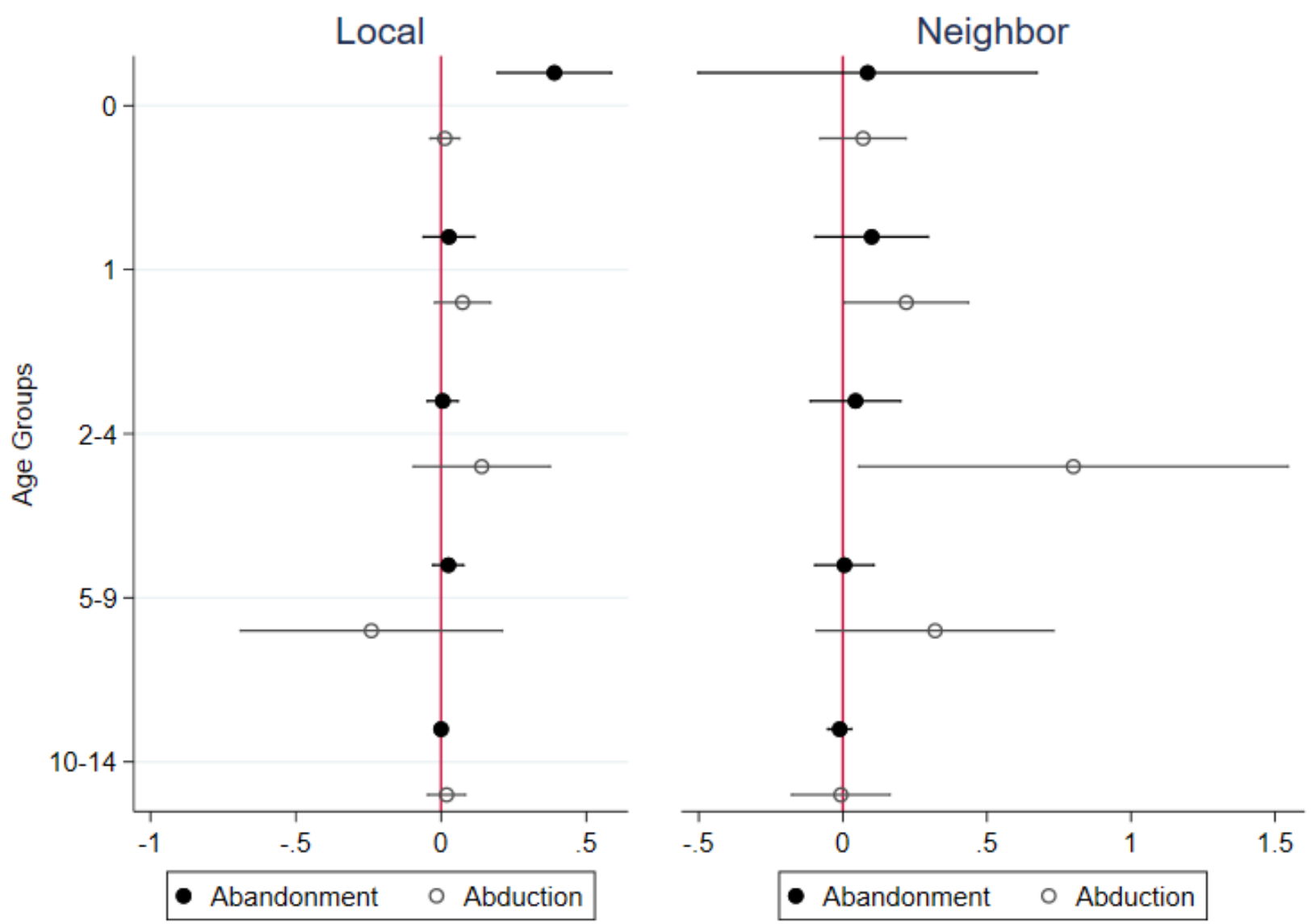

Figure 8: Coefficients of Fines on Child Abandonment and Abduction by Age Groups

Note: This figure plots out the estimated coefficients and their $95 \%$ confidence intervals of local fines and neighboring fines on child abandonment and abduction by different age groups according to the age at which a child got missing. The specific estimated coefficients are in Table OA3. 

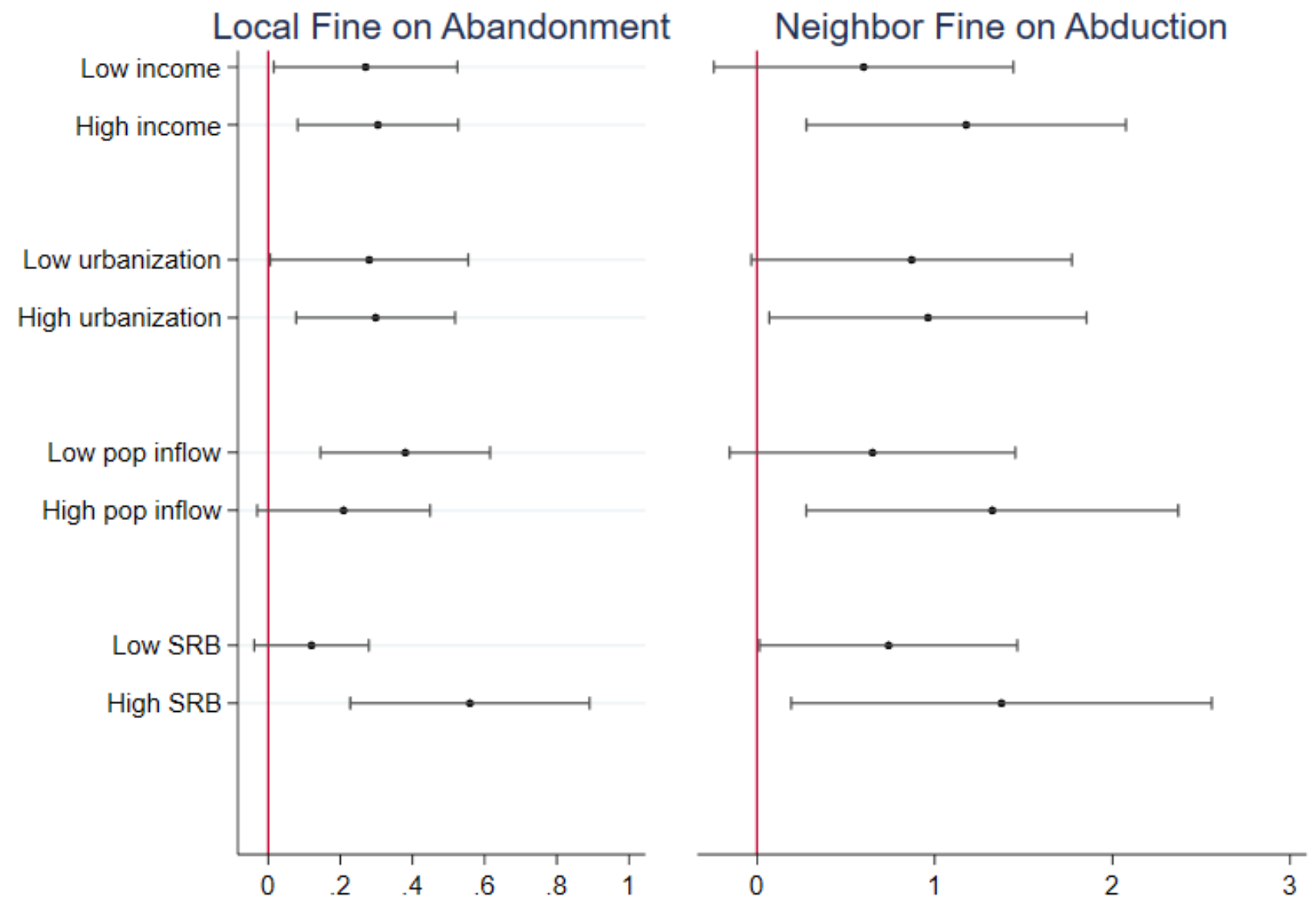

Figure 9: Heterogeneity of Impacts of Fines on Child Abandonment and Abduction by Income, Urbanization, Population Inflow and SRB

Note: This figure plots out the estimated coefficients and their $95 \%$ confidence intervals of local fines and neighboring fines on child abandonment and abduction. 


\section{Online Appendix}

Table A1: Illustration of Sample Size

\begin{tabular}{lcccccc}
\hline \multicolumn{1}{c}{ Total } & All & $\begin{array}{c}\text { Remove } \\
\text { missing }\end{array}$ & U14 & $\begin{array}{c}1988- \\
2001\end{array}$ & 2002-2016 & $\begin{array}{c}\text { Other } \\
\text { periods }\end{array}$ \\
\hline Abandonment & 16,969 & 16,882 & 16,761 & 9,037 & 852 & 5,303 \\
Abduction & 24,175 & 23,983 & 21,412 & 12,096 & 5,400 & 2,538 \\
Sum & 41,144 & 40,865 & 38,173 & 21,133 & 6,252 & 7,841 \\
\hline
\end{tabular}

Notes: Column 2 removes reported cases with missing information on age, birth year, disappearance year or disappearance locations which cannot be identified at the prefecture level. "Other periods" corresponds to 1924-1987 and 2017-2018.

Table A2: Missing Children and Fines, by Distance

\begin{tabular}{lllllll}
\hline & $(1)$ & $(2)$ & $(3)$ & $(4)$ & $(5)$ & $(6)$ \\
& Abandonment & \multicolumn{4}{l}{ Abduction } \\
& All & Boys & Girls & All & Boys & Girls \\
\hline Local fine & $0.250^{* *}$ & 0.018 & $0.230^{* * *}$ & -0.043 & -0.080 & 0.038 \\
& $(0.098)$ & $(0.040)$ & $(0.083)$ & $(0.220)$ & $(0.230)$ & $(0.054)$ \\
Fine 0-300 km & 0.071 & 0.050 & 0.021 & -0.200 & -0.160 & -0.043 \\
& $(0.110)$ & $(0.052)$ & $(0.092)$ & $(0.260)$ & $(0.240)$ & $(0.049)$ \\
Fine 300-600 km & -0.280 & -0.110 & -0.180 & $0.850^{* *}$ & $0.800^{* *}$ & 0.045 \\
& $(0.190)$ & $(0.081)$ & $(0.170)$ & $(0.390)$ & $(0.390)$ & $(0.100)$ \\
Fine 600-900 km & -0.230 & -0.055 & -0.180 & 0.320 & 0.290 & 0.032 \\
& $(0.210)$ & $(0.092)$ & $(0.180)$ & $(0.340)$ & $(0.320)$ & $(0.120)$ \\
Fine over 900 km & -0.960 & $-0.680^{* *}$ & -0.280 & -0.640 & -0.950 & 0.310 \\
& $(0.760)$ & $(0.320)$ & $(0.690)$ & $(1.230)$ & $(1.020)$ & $(0.420)$ \\
Observations & 3,363 & 3,363 & 3,363 & 3,363 & 3,363 & 3,363 \\
R-squared & 0.722 & 0.500 & 0.686 & 0.857 & 0.826 & 0.625 \\
prefFE & $\mathrm{Y}$ & $\mathrm{Y}$ & $\mathrm{Y}$ & $\mathrm{Y}$ & $\mathrm{Y}$ & $\mathrm{Y}$ \\
yearFE & $\mathrm{Y}$ & $\mathrm{Y}$ & $\mathrm{Y}$ & $\mathrm{Y}$ & $\mathrm{Y}$ & $\mathrm{Y}$ \\
preftrend & $\mathrm{Y}$ & $\mathrm{Y}$ & $\mathrm{Y}$ & $\mathrm{Y}$ & $\mathrm{Y}$ & $\mathrm{Y}$ \\
Number of clusters & 264 & 264 & 264 & 264 & 264 & 264 \\
\hline
\end{tabular}

Note: Fines in regions falling within the distance ranges are all population-weighted fines for all regions in the range. All regressions control logarithm of population density, logarithm of total criminal arrests and personal characteristics of provincial secretary and governor including their ages, age squares and on-office terms. Standard errors clustered at the prefecture level are shown in parentheses. ${ }^{* * *} \mathrm{p}<0.01, * * \mathrm{p}<0.05,{ }^{*} \mathrm{p}<0.1$ 
Table A3: Fines, SRBs and Missing Children

\begin{tabular}{|c|c|c|c|c|c|c|c|c|}
\hline & (1) & $(2)$ & (3) & (4) & (5) & (6) & (7) & (8) \\
\hline & \multicolumn{4}{|c|}{ Abandonment } & \multicolumn{4}{|c|}{ Abduction } \\
\hline & All & Girls & All & Girls & All & Boys & All & Boys \\
\hline \multirow[t]{2}{*}{ Local fine } & $-2.780 * *$ & $-2.230 *$ & $-2.720 * *$ & $-2.180 *$ & 0.006 & -0.028 & -2.140 & $-2.660 * *$ \\
\hline & $(1.380)$ & $(1.240)$ & $(1.370)$ & $(1.230)$ & $(0.220)$ & $(0.230)$ & $(1.350)$ & $(1.290)$ \\
\hline \multirow[t]{2}{*}{ Fine in 1 st-order nbr } & 0.070 & 0.016 & $-11.900 * * *$ & $-9.360 * *$ & -10.800 & -9.950 & -10.50 & -9.660 \\
\hline & $(0.240)$ & $(0.220)$ & $(4.340)$ & $(3.8500)$ & $(6.800)$ & $(6.030)$ & $(6.730)$ & (5.960) \\
\hline \multirow[t]{2}{*}{ Fine $* S R B$} & $2.650^{* *}$ & $2.130^{*}$ & $2.590^{* *}$ & $2.090^{*}$ & & & 1.850 & $2.260^{* *}$ \\
\hline & $(1.220)$ & $(1.100)$ & $(1.210)$ & $(1.090)$ & & & (1.190) & $(1.140)$ \\
\hline Fine in 1 st-order nbr & & & $10.200 * * *$ & $7.970^{* *}$ & $9.990^{*}$ & $9.210^{*}$ & $9.790^{*}$ & $8.960^{*}$ \\
\hline *nbr SRB & & & $(3.710)$ & $(3.300)$ & $(5.930)$ & $(5.290)$ & $(5.860)$ & $(5.220)$ \\
\hline Observations & 3,461 & 3,461 & 3,461 & 3,461 & 3,461 & 3,461 & 3,461 & 3,461 \\
\hline R-squared & 0.724 & 0.688 & 0.725 & 0.689 & 0.856 & 0.825 & 0.856 & 0.825 \\
\hline prefFE & $\mathrm{Y}$ & $\mathrm{Y}$ & $\mathrm{Y}$ & $\mathrm{Y}$ & $\mathrm{Y}$ & $\mathrm{Y}$ & $\mathrm{Y}$ & Y \\
\hline yearFE & Y & Y & Y & $\mathrm{Y}$ & $\mathrm{Y}$ & Y & $\mathrm{Y}$ & $\mathrm{Y}$ \\
\hline preftrend & $\mathrm{Y}$ & $\mathrm{Y}$ & $\mathrm{Y}$ & $\mathrm{Y}$ & $\mathrm{Y}$ & $\mathrm{Y}$ & $\mathrm{Y}$ & Y \\
\hline Number of clusters & 276 & 276 & 276 & 276 & 276 & 276 & 276 & 276 \\
\hline
\end{tabular}

Note: The dependent variables are the number of child abandonment and abduction separately. All regressions control logarithm of population density, logarithm of total criminal arrests and provincial secretary and governor characteristics (age, age square and terms). Prefecture-specific SRB in 2010 was dropped due to prefecture fixed effects. Standard errors clustered at the prefecture level are shown in parentheses. ${ }^{* * *} \mathrm{p}<0.01,{ }^{* *} \mathrm{p}<0.05,{ }^{*} \mathrm{p}<0.1$ 
Table A4: Fines and Missing Children, by Age Group

\begin{tabular}{llllll}
\hline & $(1)$ & $(2)$ & $(3)$ & $(4)$ & $(5)$ \\
& 0 & 1 & $2-4$ & $5-9$ & $10-14$ \\
\hline A: Abandonment & & & & & \\
Mean & 2.44 & 0.43 & 0.25 & 0.13 & 0.02 \\
\hline Local fine & $0.390^{* * *}$ & 0.027 & 0.006 & 0.025 & $-3 \mathrm{e}^{-4}$ \\
& $(0.100)$ & $(0.045)$ & $(0.027)$ & $(0.027)$ & $(0.007)$ \\
Fine in 1st-order neighbor & 0.086 & 0.100 & 0.044 & 0.005 & -0.011 \\
& $(0.300)$ & $(0.10)$ & $(0.080)$ & $(0.052)$ & $(0.021)$ \\
Observations & 2,259 & 2,259 & 2,259 & 2,259 & 2,259 \\
R-squared & 0.642 & 0.368 & 0.303 & 0.279 & 0.229 \\
Number of clusters & 265 & 265 & 265 & 265 & 265 \\
\hline B: Abduction & & & & & \\
Mean & 0.21 & 0.30 & 1.9 & 1.36 & 0.44 \\
\hline Local fine & 0.013 & 0.074 & 0.140 & -0.240 & 0.019 \\
& $(0.026)$ & $(0.049)$ & $(0.120)$ & $(0.230)$ & $(0.033)$ \\
Fine in 1st-order neighbor & 0.070 & $0.220^{* *}$ & $0.800^{* *}$ & 0.320 & -0.007 \\
& $(0.076)$ & $(0.110)$ & $(0.380)$ & $(0.210)$ & $(0.087)$ \\
Observations & 2,278 & 2,278 & 2,278 & 2,278 & 2,278 \\
R-squared & 0.320 & 0.416 & 0.829 & 0.715 & 0.412 \\
prefFE & $\mathrm{Y}$ & $\mathrm{Y}$ & $\mathrm{Y}$ & $\mathrm{Y}$ & $\mathrm{Y}$ \\
yearFE & $\mathrm{Y}$ & $\mathrm{Y}$ & $\mathrm{Y}$ & $\mathrm{Y}$ & $\mathrm{Y}$ \\
Preftrend & $\mathrm{Y}$ & $\mathrm{Y}$ & $\mathrm{Y}$ & $\mathrm{Y}$ & $\mathrm{Y}$ \\
Number of clusters & 264 & 264 & 264 & 264 & 264 \\
\hline
\end{tabular}

Note: All regressions control logarithm of population density, logarithm of total criminal arrests and personal characteristics of provincial secretary and governor including their ages, age squares and on-office terms. Standard errors clustered at the prefecture level are shown in parentheses. ${ }^{* * *} \mathrm{p}<0.01,{ }^{* *} \mathrm{p}<0.05, * \mathrm{p}<0.1$ 
Table A5: Fines, Missing Children and SRB in Multiple Years

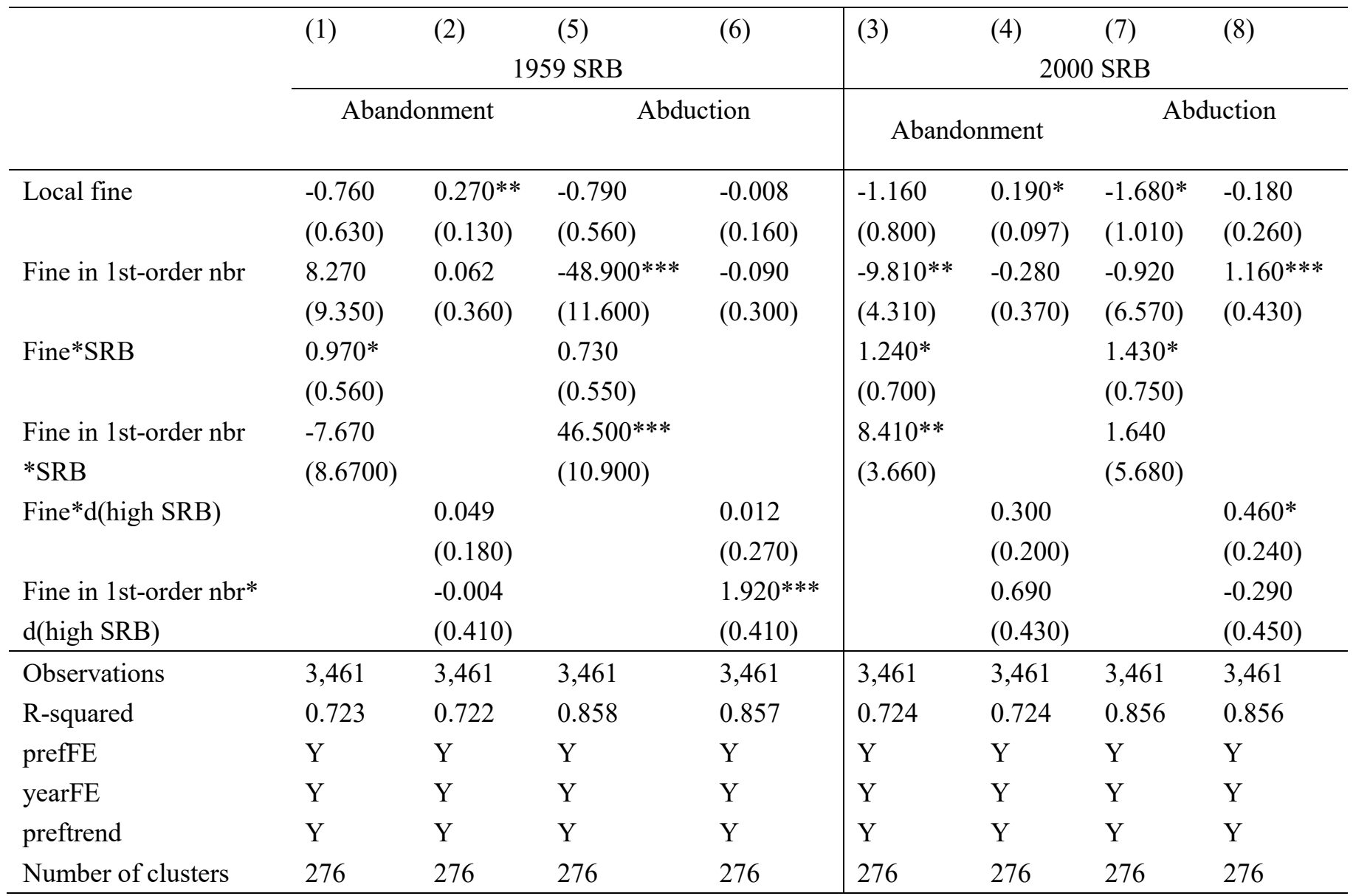

Note: All regressions control logarithm of population density, logarithm of total criminal arrests and provincial secretary and governor characteristics (age, age square and terms). A prefecture is classified as having a strong preference for boys if the sex ratio at birth (SRB) was no less than 1.07 in 1959 or no less than ?? in 2000. Standard errors clustered at the prefecture level are shown in parentheses. ${ }^{* * *} \mathrm{p}<0.01,{ }^{* *} \mathrm{p}<0.05,{ }^{*} \mathrm{p}<0.1$ 


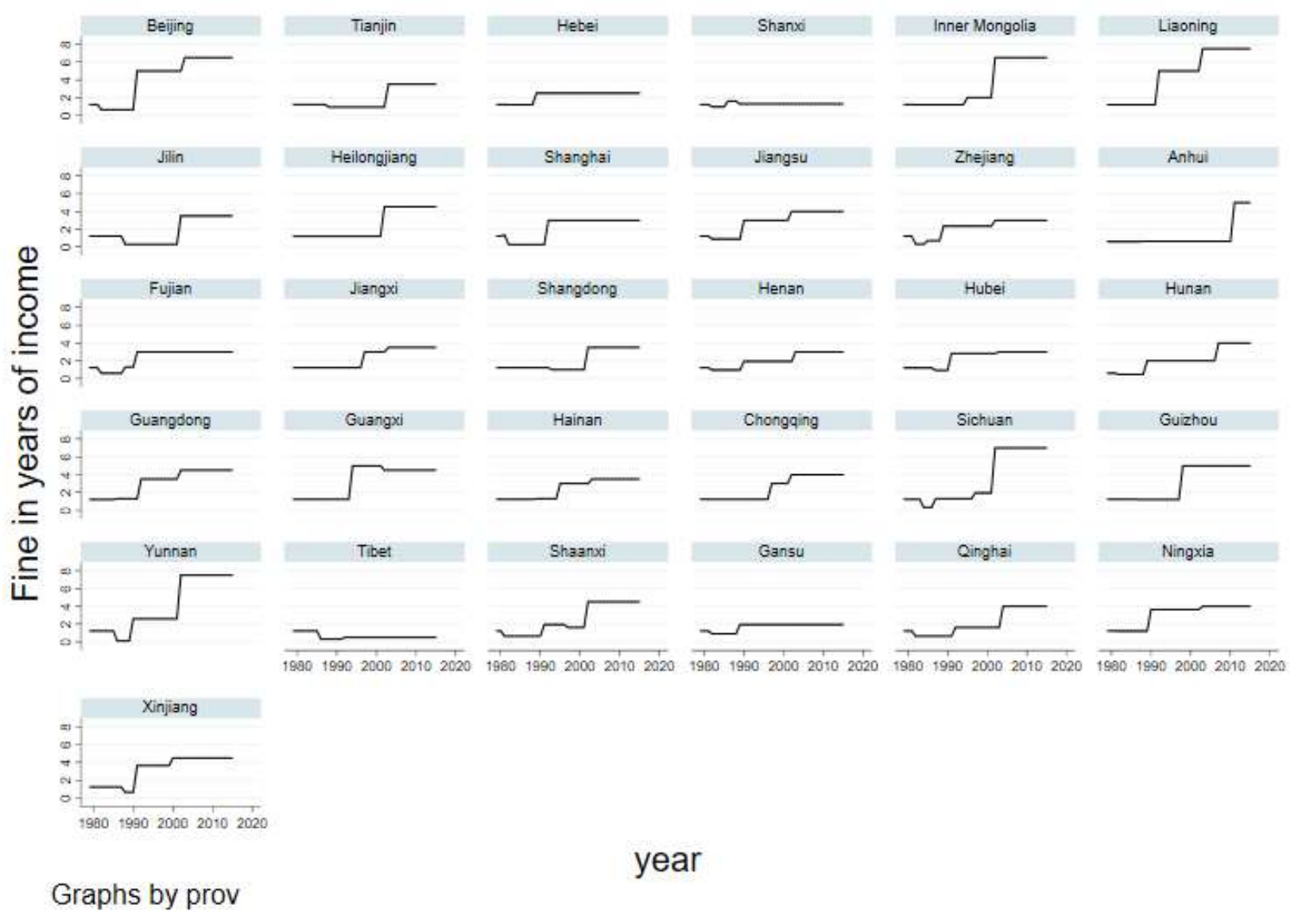

Figure A1: Variations in Fines, by Province (1980-2016) 


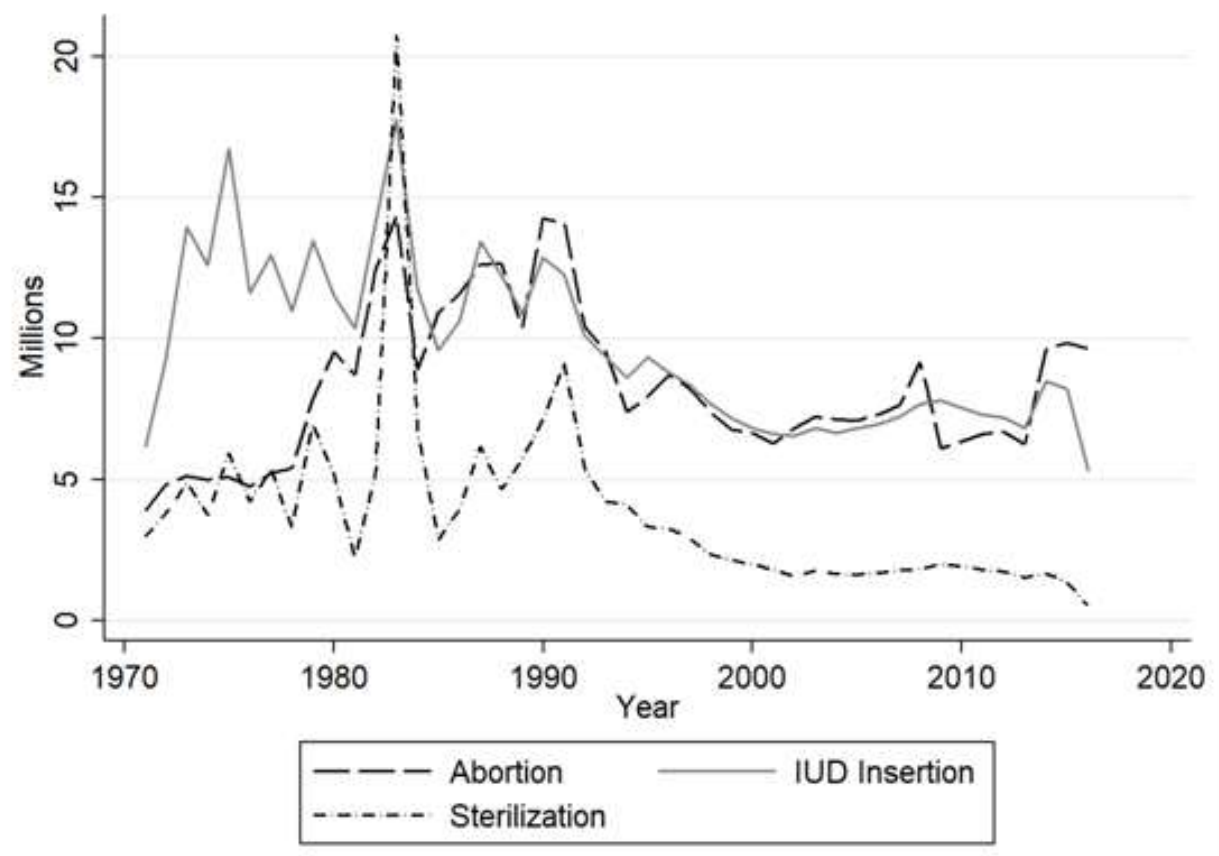

Figure A2: Number of Birth-Control Operations in China: 1971-2016

- Type: family looking for child

- ID:18081

- Name:

- Gender: Male

- Birth Date: 1988/07/06

- Height when lost: about $80 \mathrm{~cm}$

- Lost Date: 1991/2/20

- Residence of the lost person

- Lost location: Guangdong Chaoshan

- Descriptions:

- Other info

- Registration date

- Follow-up volunteer

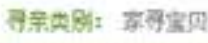

쿠연류: 13031

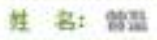

仕 Bit 畹

出的是: 1968年07月06日

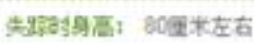

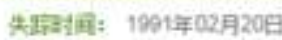

失轻人所在为:

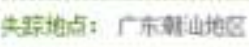

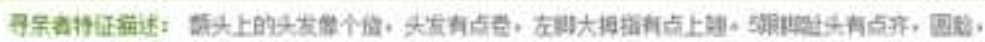

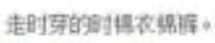

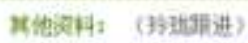

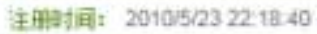

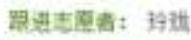

Figure A3: Example of Missing Child Case Reported to BCBH 


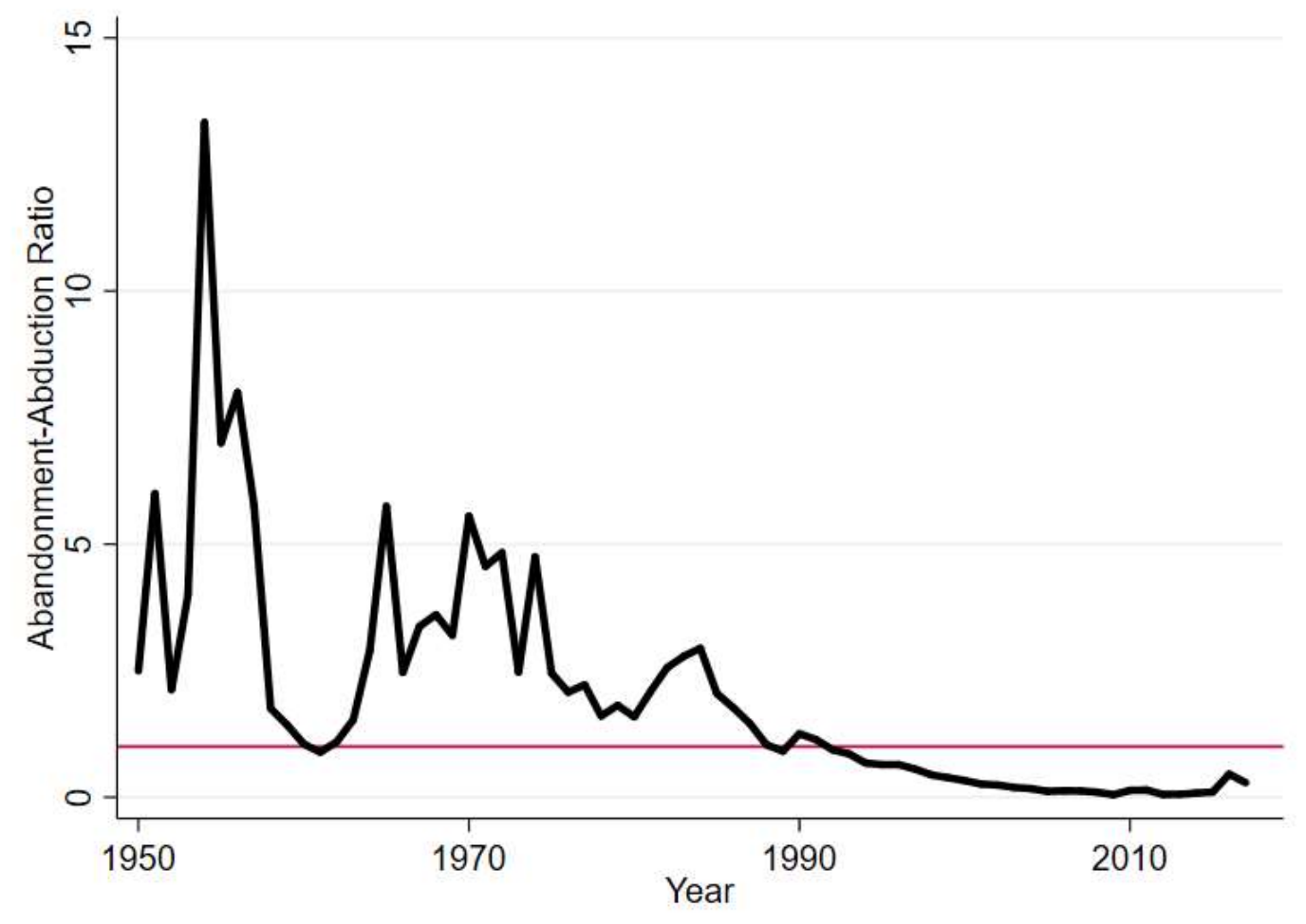

Figure A4: Ratio of Abandonment/Abduction Based on Family-reported Missing Children

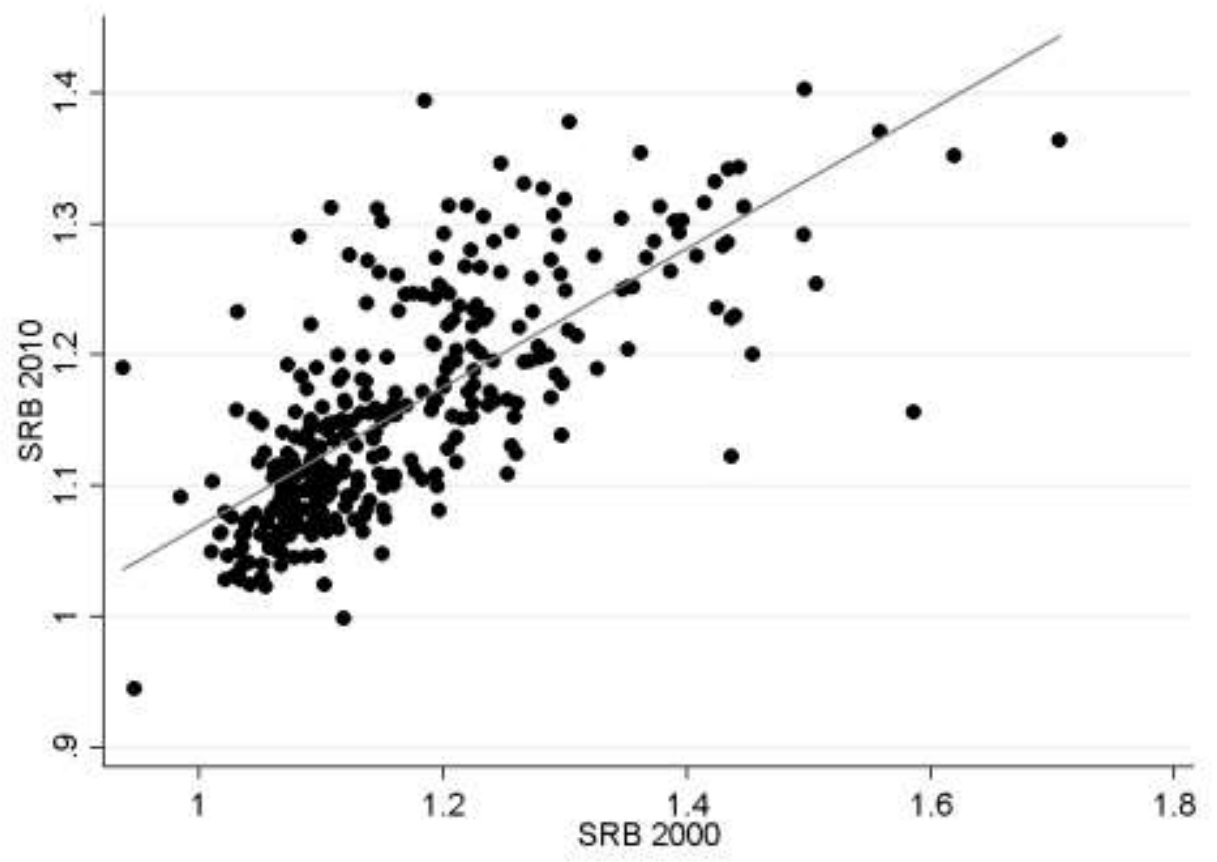

Figure A5: Sex Ratio at Birth in Chinese Prefectures: 2000-2010 